\title{
COLLABORATING DURING CORONAVIRUS: THE IMPACT OF COVID-19 ON THE NATURE OF WORK
}

\author{
Evan DeFilippis \\ Stephen Michael Impink \\ Madison Singell \\ Jeffrey T. Polzer \\ Raffaella Sadun \\ Working Paper 27612 \\ http://www.nber.org/papers/w27612 \\ NATIONAL BUREAU OF ECONOMIC RESEARCH \\ 1050 Massachusetts Avenue \\ Cambridge, MA 02138 \\ July 2020
}

The views expressed herein are those of the authors and do not necessarily reflect the views of the National Bureau of Economic Research.

NBER working papers are circulated for discussion and comment purposes. They have not been peerreviewed or been subject to the review by the NBER Board of Directors that accompanies official NBER publications.

(C) 2020 by Evan DeFilippis, Stephen Michael Impink, Madison Singell, Jeffrey T. Polzer, and Raffaella Sadun. All rights reserved. Short sections of text, not to exceed two paragraphs, may be quoted without explicit permission provided that full credit, including $\odot$ notice, is given to the source. 
Collaborating During Coronavirus: The Impact of COVID-19 on the Nature of Work

Evan DeFilippis, Stephen Michael Impink, Madison Singell, Jeffrey T. Polzer, and Raffaella

Sadun

NBER Working Paper No. 27612

July 2020

JEL No. L2,L23,M0

\section{ABSTRACT}

We explore the impact of COVID-19 on employee's digital communication patterns through an event study of lockdowns in 16 large metropolitan areas in North America, Europe and the Middle East. Using de- identified, aggregated meeting and email meta-data from 3,143,270 users, we find, compared to pre- pandemic levels, increases in the number of meetings per person (+12.9 percent) and the number of attendees per meeting ( +13.5 percent), but decreases in the average length of meetings (-20.1 percent). Collectively, the net effect is that people spent less time in meetings per day (-11.5 percent) in the post- lockdown period. We also find significant and durable increases in length of the average workday ( +8.2 percent, or +48.5 minutes), along with short-term increases in email activity. These findings provide insight from a novel dataset into how the nature of work has changed for a large sample of knowledge workers. We discuss these changes in light of the ongoing challenges faced by organizations and workers struggling to adapt and perform in the face of a global pandemic.

\author{
Evan DeFilippis \\ Harvard Business School \\ Soldiers Field \\ Boston, MA 02163 \\ edefilippis@hbs.edu \\ Stephen Michael Impink \\ 44 West 4th Street \\ New York, NY 10012 \\ simpink@stern.nyu.edu \\ Madison Singell \\ Harvard Business School \\ Soldiers Field \\ Boston, MA 02163 \\ msingell@hbs.edu
}

\author{
Jeffrey T. Polzer \\ Harvard Business School \\ Soldiers Field \\ Boston, MA 02163 \\ jpolzer@hbs.edu \\ Raffaella Sadun \\ Harvard Business School \\ Morgan Hall 233 \\ Soldiers Field \\ Boston, MA 02163 \\ and NBER \\ rsadun@hbs.edu
}




\section{Introduction}

The COVID-19 global pandemic has disrupted the way organizations function, just as it has disrupted life more generally. As the number of infections increased, governments across the globe closed their borders and shut down physical work sites in an attempt to reduce the spread of infection caused by the virus. As of April 7, 2020, 95 percent of Americans were required to shelter-in-place within their homes, similar to the citizens of many other countries. Organizations have responded by altering their work arrangements to accommodate these new realities, including a rapid shift to working from home for large segments of knowledge workers. Given the large scale economic and social upheaval wrought by COVID-19, this abrupt transition to remote work occurs at a time when organizational coordination, decision-making processes, and productivity have never been more consequential.

The global policy response to COVID-19 represents an unprecedented natural experiment in which, for the first time, many organizations across the world find themselves with a fully physically dispersed workforce. Moreover, employees had to quickly shift to relying on digital communication technologies to perform their job regardless of how conducive their home environment or task requirements were to such arrangements. While most knowledge workers had engaged in some form of remote work prior to the pandemic, they typically did so with the support of colleagues physically co-located in a centralized office (Raghuram et al., 2019).

For all the anecdotes and speculation about working from home during the pandemic, there is still little systematic evidence about how employees have changed their day-to-day work activities as a consequence of these unexpected shocks. In particular, how have employees changed their patterns of digital communication -- e.g., meetings and emails -- to compensate for the lack of face-to-face conversation that typically occurs in a physical workplace? Have various dimensions of meeting and email activity, such as their frequency or scope, changed as employees and organizations adapt to a new working environment? Generalizing from past research on work from home arrangements is challenging, given that most remote work prior to COVID-19 was voluntary, less widespread, and performed under less dramatic circumstances (Bloom et al., 2015; Choudhury et al., 2019).

This paper provides the first large scale analysis of how digital communication patterns have changed in the early stages of the pandemic. To study this question, we acquired de-identified, aggregated meta-data from an information technology services provider that licenses digital communications solutions to organizations around the world. We use aggregated digital meta-data on emails and meetings for 3,143,270 users across 21,478 de-identified firms in 16 large metropolitan areas, aggregated by the provider to the level of Metropolitan Statistical Area (MSA) and day, across all available firms (see Appendix, Figure S1 and S2). The meta-data provides information on both email and meeting frequency, as well as other salient aspects of digital communications and interactions such as meeting size and duration, the number of email recipients, and the time emails are sent, among other dimensions (see Appendix, Table S1).

We selected 16 Metropolitan Statistical Areas (MSAs) that have experienced governmentmandated lockdowns. These lockdowns established a clear breakpoint after which we could infer that people were working from home. The earliest lockdown in our data occurred on March 8, 2020, in Milan, Italy, and the latest lockdown occurred on March 25, 2020, in Washington, DC (see Table 1 for more information). We report data from a window starting eight weeks prior to the lockdown and ending eight weeks after the lockdown in each MSA to explore how the behavior of workers changed. 
In analyzing digital communication patterns across a large number of firms and regions, we build upon an emerging literature that uses communication meta-data to measure otherwise hidden networks and patterns of communication (Impink et al., 2020; Polzer et al., 2018). Other studies have used similar metadata to reveal the importance of meeting and email patterns for a variety of organizational outcomes (Kleinbaum et al., 2013; Srivastava et al., 2018).

\section{Table 1: Lockdown Dates}

\begin{tabular}{|c|c|c|}
\hline \multirow[b]{2}{*}{ MSA } & \multicolumn{2}{|c|}{ Dates } \\
\hline & $\begin{array}{c}100 \\
\text { Cases }\end{array}$ & Lockdown \\
\hline Milan & 20-Feb & 8-Mar \\
\hline Rome & 20-Feb & 10-Mar \\
\hline Osla & 4-Mar & 12-Mar \\
\hline Madrid & 28-Feb & 14-Mar \\
\hline Zurich & 2-Mar & 16-Mar \\
\hline Geneva & 2-Mar & 16-Mar \\
\hline San Jose & 10-Mar & 16-Mar \\
\hline Paris & 10-Feb & 17-Mar \\
\hline San Francisco & 10-Mar & 17-Mar \\
\hline Brussels & 5-Mar & 18-Mar \\
\hline Tel Aviv & 6-Mar & 19-Mar \\
\hline Chicago & 27-Feb & 21-Mar \\
\hline New York City & 10-Mar & 21-Mar \\
\hline London & 17-Feb & 24-Mar \\
\hline Washington, D.C. & 14-Mar & 25-Mar \\
\hline
\end{tabular}

\section{Results}

Our primary objects of investigation are average measures of digital communication patterns built from collaboration metadata, aggregated at the MSA-day level. We use a regression-based event study to examine how these measures vary before and after government-mandated lockdowns.1 For the purpose of our study, we grouped digital communication measures into two categories of interest: meeting and email activity.

The total amount of time employees in any firm collectively spend in meetings is a function of three parameters that can vary independently: average meeting duration, average meeting size, and total number of meetings. We find an increase in the total count of meetings per person per day $(+12.9 \%$ [CI: $+11.4 \%$ to $+14.4 \%],+0.8$ meetings per person per day) 2 , an increase in the average number of attendees per meeting $(+13.5 \%$ [ $+10.6 \%$ to $+16.5 \%],+2.1$ attendees per meeting), and a decrease in the average duration of meetings (-20.1\% [-23.0\% to $-17.1 \%],-12.1$ minutes per meeting). That is, organizations in the post-lockdown period appeared to have more frequent meetings with more attendees, and shorter meetings, compared to the prior period. The net effect of these changes was to significantly reduce the total number of hours employees spent in meetings during the post-lockdown period (-11.5\% [-14.3\% to -8.7\%], -18.6 minutes per person per day). All of these results are significant at the $\mathrm{p}<.001$ level. 
For daily email activity, we find that several email measures increased in the post-lockdown period. Specifically, we find significant increases in the average number of emails sent and received among people from the same organization, which we refer to as internal emails ( $+5.2 \%$ [ $+3.0 \%$ to $7.6 \%$ ], +1.4 emails per person per day). We also find that there was a significant increase in the average number of recipients included on emails sent in the post-lockdown period $(+2.9 \%$ [ $+0.3 \%$ to $+5.5 \%],+0.25$ recipients per email sent). However, external emails and distinct emails sent (unique emails counted only once, regardless of the number of internal or external recipients) did not significantly change in the post-lockdown period.

Using the span of time defined by the first and last email sent or meeting attended in a 24-hour period, we also find the average workday span increased by +48.5 minutes $(+8.2 \%[+7.1 \%$ to $+9.3 \%])$, partly due to increases in emails sent after business hours $(+8.3 \%$ [ $+4.0 \%$ to $12.7 \%$ ], +0.63 emails per person per day). The results for these post-lockdown changes of meeting and email variables are further detailed in Appendix, Table S2. Results, except for that of email recipients, are robust to weighting regressions by the total number of users in each MSA, with an additional positive and significant result for emails sent distinct under this specification, Appendix Table S3.

After assessing the overall post-lockdown changes in communication activities, we conducted more granular tests to understand how these changes unfolded week by week. Again using regression analyses, we computed the weekly change in digital communication patterns following the enacted lockdown relative to a base week. Given that communication patterns within a given MSA began to change about a week prior to the formal lockdown date, we defined our base week as one week prior to the week in which the lockdown occurred, where the lockdown day occurs at the midpoint of the lockdown week. The coefficients denoting the changes in communication relative to the base week, and corresponding standard errors, are shown in Table 2 for meeting variables and Table 3 for email variables, and Figure 1 and Figure 2 visualize these meeting and email findings respectively.

\section{Figuire 1: Impact of COVID-19 Lockdown on Meetings}

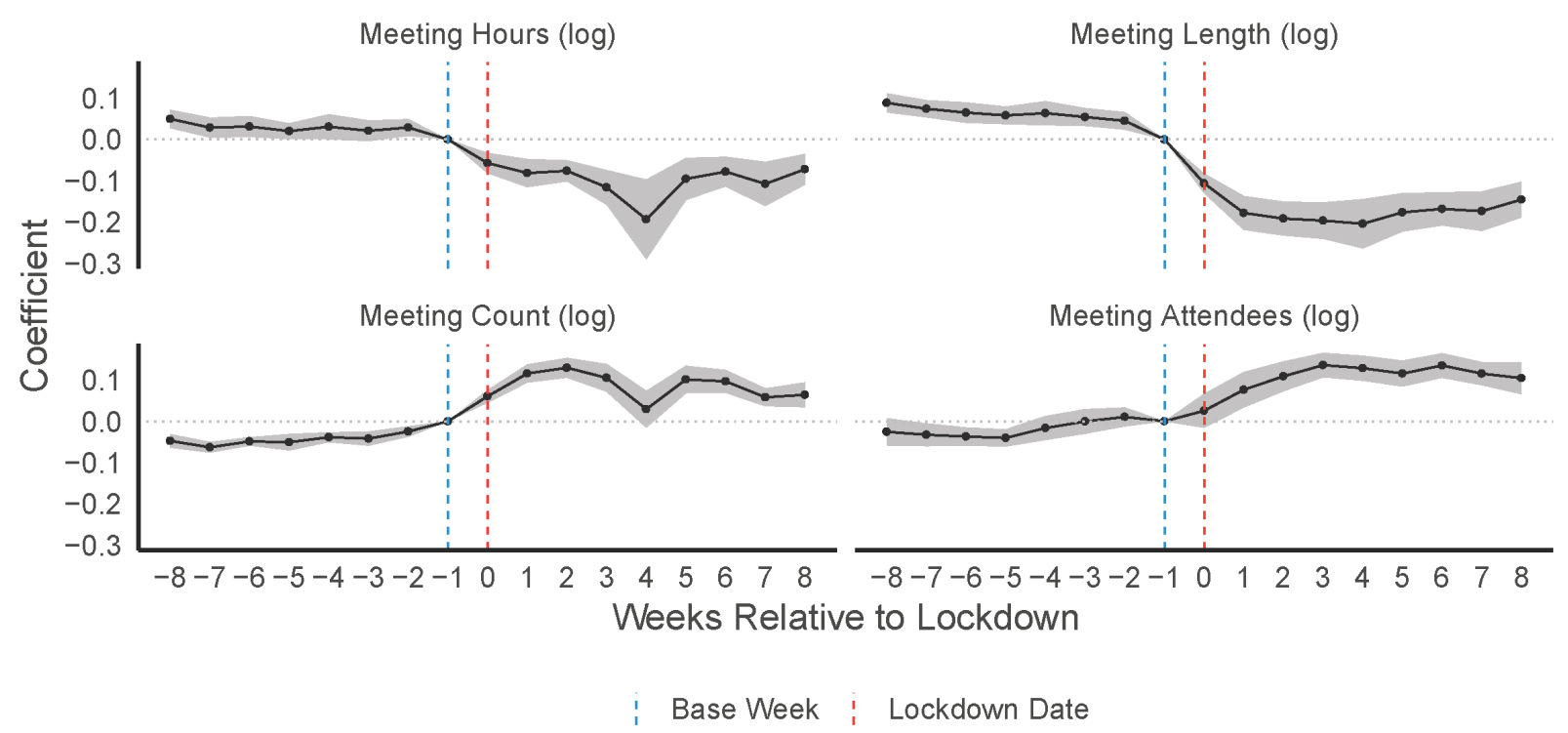

DeFilippis et al. (2020) | 4 
For meeting variables, we find consistent increases in the size and count of meetings and consistent decreases in the length of meetings each week after the lockdown date. The cumulative effect of these changes is to consistently decrease the total amount of hours employees spend in meetings each week after the lockdown date.

For email variables, we find a more varied pattern of results. The total number of distinct, internal, and external emails sent increased sharply the week of the lockdown and then persistently decreased each week, returning to pre-lockdown levels or below by week four. The average number of recipients per email demonstrated a similar effect, with a small spike the week of the lockdown followed by a gradual levelling out. Note, however, that by week eight, the average number of recipients per email remained significantly higher than the level eight weeks prior to lockdown (See Appendix, S5). The effect of the lockdown on workday span was more consistent -- the average workday span of an employee was higher in every week following the lockdown than any week in the eight weeks prior to the lockdown.

\section{Figure 2: Impact of COVID-19 Lockdown on Emails}

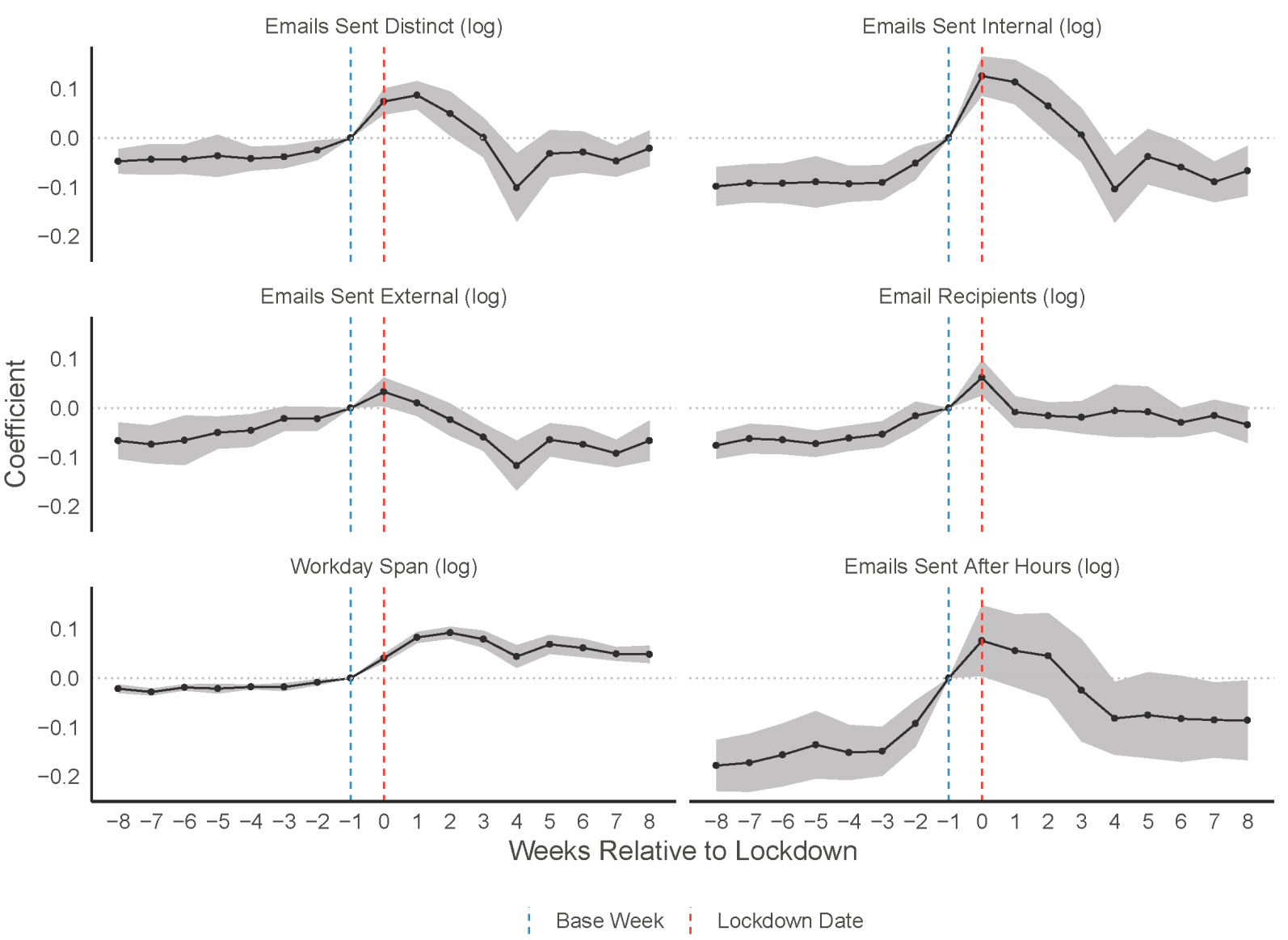

Careful inspection of these weekly results reveals that some communication patterns began to change even earlier than one week before the lockdown. To account for this variation, in Appendix Figure S4 and Figure S5, we recreate Model 2, but we set the reference category to eight weeks prior to the lockdown date in order to formally test whether meeting and email trends eight weeks into a lockdown were different from the trends observed eight weeks prior to the lockdown. We find that, for the meeting 
variables, the changes that occurred after the lockdown persisted over time. Specifically, compared to meeting activity eight weeks prior to the lockdown, the decreases in average meeting length and meeting hours that we observed were maintained throughout the post-lockdown period. At the same time, the average meeting size and number of meetings remained higher throughout the post-lockdown period.

Results from Appendix Figure S5 also clarify the long-term trends in email activity. We find that the overall increase in email activity that characterized the post-lockdown period was most prominent in the two weeks immediately after the lockdown announcements. By the fourth week after the lockdown, the number of internal, external, and distinct emails sent returned to the level of the pre-lockdown period. Changes to the remaining variables were more persistent; the average number of recipients per email remained higher throughout the post-lockdown period, as did the workday span and the number of emails received after hours, compared to eight weeks prior to the lockdown.

We report a number of supplemental results in the Appendix. Two additional meeting variables representing online and multi-country meetings both exhibited initial increases during and immediately after the lockdown before trending back toward pre-lockdown levels (See Appendix, Table S4 and Figure S3). Multi-country meetings in particular exhibited a noteworthy trend, with an initial increase in week one, followed by a steady decrease every week for the following seven weeks. By week eight, the number of multi-country meetings was significantly less than the numbers reported both one and eight weeks prior to the lockdown.

We also break down our results by MSA to reveal some interesting geographical variation in meeting and email activity. Meeting length declined in every MSA but exhibited substantial variation in the slope of the decrease. In many European cities such as Brussels, Oslo, and Zurich, for example, the decrease in meeting length was sharp and continued to drop for four weeks after the lockdown, while in U.S. cities like Chicago, New York City, and Washington D.C., the decrease in meeting length was relatively small and stabilized a week after the lockdown. The span of workdays increased in all cities, but remained high in some (e.g., San Jose, Rome, New York City) while returning to baseline in others. These

and related results broken down by MSA appear in the Appendix, Figures S6-S15. Note that many of the MSA-specific graphs (e.g. Appendix, Figure S6) show evidence of being influenced by religious holidays -- specifically, Easter in European cities and Passover in Israel -- which occurs around week four for most MSAs. The timing of these holidays corresponds with sharp decreases in the level of meeting and email activity in the MSAs for which Easter and Passover are federal holidays.

\section{Discussion}

With the COVID-19 pandemic forcing employees around the world to work from home, the need to communicate effectively has never been greater. Yet, the ability of employees to communicate has changed dramatically with the loss of a centralized office and the face-to-face interaction it fosters.

To investigate this phenomenon, we conducted a large-scale event study of COVID-related lockdowns and found that employees significantly changed their communication activities when working remotely. In the weeks immediately following the lockdown, employees increased the number of meetings they attended and the number of emails they sent. We also found increases in the number of attendees per meeting, on average, and the number of recipients per email. That is, employees expanded both the frequency and the scope of their communications. 
Employees also adjusted their work schedules, extending the range of time they worked, as indicated by the first and last email or meeting of a day, and sending more emails outside of working hours. Not all communication activities increased, however. The average length of meetings decreased to such an extent that the collective amount of time employees spent in meetings decreased, even though the total number of meetings and the total number of attendees in those meetings increased over the same period.

These results, taken together, document an increase in employees' meeting and email activity in terms of frequency, the number of people included, and the range of time spent engaging in these activities. These patterns are consistent with the need to use virtual forms of communication to replace the face-toface interaction typical in an office setting, while adapting to the extraordinary disruption caused by the crisis.

Though an overarching increase in virtual communication is unsurprising, we would not have predicted all of the ways in which this occurred. For example, despite the potential drawbacks of large meetings or emails with many recipients, these forms of communication practices may help synchronize how information is shared (e.g., by holding a team meeting instead of several one-on-ones). Moreover, expanding the number of email recipients and meeting attendees increases the likelihood that important information is received by all relevant individuals in an organization. This is an especially important function in a time when organizational challenges likely cut across the business and are relevant to a greater set of people. Being more inclusive when everyone is dispersed could also help employees maintain their identification with the organization (Wiesenfeld et al., 1999).

At first glance, our finding that meetings have become shorter seems to cut against the broader pattern described above. However, meeting length is not independent of meeting frequency or size. To coordinate many calendars, employees may find it necessary to shorten meetings in order to accommodate more frequent meetings with more attendees. The relationship of these meeting parameters is also relevant at the organizational level, where the aggregate number of hours people spend in meetings is a function of three variables: the total count of meetings, the average meeting size, and the average meeting duration. Because we observe a net decrease in the total number of hours that employees spent in meetings after lockdowns, it must be the case that the reduction in the duration of meetings dominated the effects of having larger and more frequent meetings.

Though speculative, it is possible that employees also find it harder to stay engaged in long virtual meetings compared to in-person meetings (Wasson, 2004). An employee's attention span may be additionally strained by challenges specific to the COVID-19 pandemic, such as taking care of children who are not in school. Another possibility is that the function of meetings has changed in the post-lockdown period. The lockdown introduced a host of new problems requiring unplanned, emergent coordination, much of which could be addressed through impromptu interaction if everyone were in the same office. With everyone working at home, however, short meetings could serve to quickly communicate new plans, share work that has been accomplished, increase accountability, calibrate priorities, provide social support, and achieve other purposes that are often handled informally in office settings.

Consistent with the overall pattern of more meetings and more emails, our findings also point to a spillover of virtual communication beyond normal working hours. After all, one way to achieve more communication is to work longer days. Even with reduced time spent in meetings, the work demands 
brought about by the pandemic, coupled with personal demands that are always close at hand, could make it hard to meet obligations within the bounds of normal working hours.

It is unclear if this increase in average workday span represents a benefit or drawback to employee well-being. On one hand, the flexibility to choose one's working hours to accommodate household demands may empower employees by affording them some freedom over their own schedule. On the other hand, the change in work schedule may be a consequence of a blurred distinction between work and personal life, in which it becomes easy to overwork due to the lack of clear delineation between the office and home.

Given the unprecedented nature of the changes wrought by COVID-19, it was unclear from the outset how employees would adapt their communication patterns as they transitioned to working from outside their offices. Our findings provide strong evidence that employees adjusted their internal communications in response to COVID-19 lockdowns, even prior to formal policy changes. Indeed, the fact that patterns of email and meeting activity began to change, on average, about a week prior to formal lockdown issuances, suggest that organizations can rapidly adjust their communication patterns in anticipation of formal policy requirements, or in response to local environmental conditions (e.g. the increasing spread of the virus in workplaces.) It will remain to be seen whether these changes persist as employees continue to adapt to working from home during a pandemic and, eventually, when the requirements to do so are lifted.

\section{Materials and Methods}

We analyzed a novel sample of aggregated meeting and email meta-data from 3,143,270 users across 21,478 firms in 16 international cities that have been affected by official lockdown orders, reported in Appendix, Figure S1 and S2. From this meta-data, our provider built measures of the communication frequency for email (the average count of distinct, internal and external emails and the average count of recipients) and meetings (the average count of meetings, average meeting duration, and average count of meeting attendees). Additionally, we measured broader changes to the nature of work, such as the average length of workday (measured from the first communication to the last communication in a given day) and the average number of emails sent outside of normal business hours, reported in Appendix, Table S1.

The provider aggregated meeting and email data to a list of Metropolitan Statistical Areas (MSAs) through a probabilistic record linkage algorithm. For each MSA in our data, we included the central business district of the cities and surrounding suburbs and townships within the MSA with populations greater than 100,000 people. The average population of the MSAs in our sample is around 6.2 million people, ranging from roughly 1 million (Geneva, Switzerland) to 20 million (New York City, USA) people. All of the cities in the sample have experienced a government-mandated lockdown. Note that every variable used in this analysis was computed by our provider and delivered to us pre-aggregated at the MSA-level. At no point did the research team have access to personally identifiable or user-level data.

For the main set of results, we used average meeting and email activity aggregated at the MSA-day level in the post-lockdown period relative to the pre-lockdown period. We used the following specification for our first set of results, which uses a single dummy variable to test the overall difference between preand post-lockdown periods for each outcome variable.

$$
y i, t=\beta 0+\beta 1 \text { post }+\gamma i+d t+u i, t
$$


To analyze the change in email and meeting measures over different weeks, we used the following specification:

$$
y i, t=\beta 0+\sum_{r=-8}^{-2} \beta_{t}^{L} \times D \tau_{t}+\sum_{r=0}^{8} \beta_{t}^{L} \times D \tau_{t}+\gamma_{i}+d_{t}+u_{i, t}
$$

where $y i, t$ are logged email and meeting data at the $M S A i$ and dayt level, post is an indicator variable for the time period after lockdown, $D \tau_{t}$ is a week indicator variable, relative to the lockdown week, $\gamma_{i}$ are MSA-level fixed effects, and $d_{t}$ are day of the week indicator variables (Monday, Tuesday, Wednesday, etc.).

This design controls for characteristics of MSAs which are time invariant, or MSA fixed effects. The "lockdown week" is the 7-day period that includes the lockdown date at its center. Every prior and subsequent week indicator is defined relative to that week. The base week for our regression is defined as one week prior to the lockdown week since many organizations began making arrangements days in advance of official lockdowns based on news of impending policy changes. Email and meeting measures do not display evidence of a pre-trend in the weeks leading up to the base week and lockdown week. All standard errors are clustered at the MSA level. (See Table 2 and Table 3 for details).

\section{Discussion}

While our data establish that employees changed their pattern of email and meeting activity in response to lockdowns, our findings are not without limitations. First, we do not have access to meta-data concerning the content of meetings or emails. As such, we cannot corroborate whether the purpose of emails and meetings has changed in the post-lockdown period. Future research with more granular data could reveal how firms of different sizes, working in different industries, and with different capacities to shift to remote work, have adjusted to working from home.

A second limitation is that we are unable to identify specific firms or organizations from the dataset, so we cannot fully determine the extent to which the changes in communication patterns are driven by changes to the supply of work or to changes in the demand for products and services. Related to this, we treat all government-mandated lockdowns as similar in terms of their influence on organizational communication. In actuality, the nature and severity of these lockdowns differ by MSA and by type of business. Future research should classify lockdowns and stages of reopening based on their requirements, and classify firms by size and industry, to understand better how variations in these policies influence organizational performance and behavior.

A third limitation is that because the data consist of aggregated averages, we are unable to identify individuals or match the data with demographic information. As such, we cannot determine whether the move to remote work affected certain subsets of people differently than others.

Finally, it is important to describe how changes in communication are associated with broader changes in the nature of work. While our findings show that an average employee's "workday span" has increased in the post-lockdown period, it is unclear if employees are actually working longer hours, or if 
they have just adopted a non-standard work schedule. Future research should identify at an individual-level how employees change their time and attention devoted to organizational work when large proportions of them work from home. 


\begin{tabular}{|c|c|c|c|c|}
\hline & \multicolumn{4}{|c|}{ Dependent variable: } \\
\hline & $\begin{array}{l}\text { Meeting Hours (log) } \\
\text { (1) }\end{array}$ & $\begin{array}{l}\text { Meeting Length (log) } \\
\text { (2) }\end{array}$ & $\begin{array}{l}\text { Meeting Count } \\
\text { (log) } \\
\text { (3) }\end{array}$ & $\begin{array}{c}\text { Meeting } \\
\text { Attendees (log) } \\
\text { (4) }\end{array}$ \\
\hline -8 Weeks from Lockdown & $\begin{array}{c}0.050^{* * *} \\
(0.011)\end{array}$ & $\begin{array}{l}0.089^{* * *} \\
(0.012)\end{array}$ & $\begin{array}{c}-0.048^{* * *} \\
(0.008)\end{array}$ & $\begin{array}{l}-0.025 \\
(0.017)\end{array}$ \\
\hline -7 Weeks from Lockdown & $\begin{array}{c}0.029^{*} \\
(0.012)\end{array}$ & $\begin{array}{l}0.075^{* * *} \\
(0.011)\end{array}$ & $\begin{array}{c}-0.063^{* * *} \\
(0.006)\end{array}$ & $\begin{array}{l}-0.033^{*} \\
(0.014)\end{array}$ \\
\hline -6 Weeks from Lockdown & $\begin{array}{c}0.031^{*} \\
(0.013)\end{array}$ & $\begin{array}{c}0.065^{* * *} \\
(0.013)\end{array}$ & $\begin{array}{c}-0.049^{* * *} \\
(0.005)\end{array}$ & $\begin{array}{l}-0.037^{* *} \\
(0.011)\end{array}$ \\
\hline -5 Weeks from Lockdown & $\begin{array}{c}0.020 \\
(0.010)\end{array}$ & $\begin{array}{c}0.058^{* * *} \\
(0.011)\end{array}$ & $\begin{array}{c}-0.051^{* * *} \\
(0.010)\end{array}$ & $\begin{array}{c}-0.040^{* *} \\
(0.010)\end{array}$ \\
\hline -4 Weeks from Lockdown & $\begin{array}{c}0.031 \\
(0.015)\end{array}$ & $\begin{array}{l}0.064^{* * *} \\
(0.015)\end{array}$ & $\begin{array}{c}-0.039^{* * *} \\
(0.006)\end{array}$ & $\begin{array}{l}-0.016 \\
(0.015)\end{array}$ \\
\hline -3 Weeks from Lockdown & $\begin{array}{c}0.021 \\
(0.013)\end{array}$ & $\begin{array}{l}0.055^{* * *} \\
(0.011)\end{array}$ & $\begin{array}{c}-0.042^{* * *} \\
(0.009)\end{array}$ & $\begin{array}{r}-0.0003 \\
(0.015)\end{array}$ \\
\hline -2 Weeks from Lockdown & $\begin{array}{c}0.029^{*} \\
(0.010)\end{array}$ & $\begin{array}{c}0.045^{* * *} \\
(0.011)\end{array}$ & $\begin{array}{c}-0.025^{* *} \\
(0.006)\end{array}$ & $\begin{array}{c}0.011 \\
(0.012)\end{array}$ \\
\hline Lockdown Week & $\begin{array}{c}-0.057^{* * *} \\
(0.012)\end{array}$ & $\begin{array}{c}-0.106^{* * *} \\
(0.012)\end{array}$ & $\begin{array}{l}0.061^{* * *} \\
(0.008)\end{array}$ & $\begin{array}{c}0.026 \\
(0.021)\end{array}$ \\
\hline +1 Week from Lockdown & $\begin{array}{c}-0.081^{* * *} \\
(0.017)\end{array}$ & $\begin{array}{c}-0.178^{* * *} \\
(0.021)\end{array}$ & $\begin{array}{c}0.116^{* * *} \\
(0.011)\end{array}$ & $\begin{array}{l}0.077^{* *} \\
(0.022)\end{array}$ \\
\hline +2 Weeks from Lockdown & $\begin{array}{c}-0.076^{* * *} \\
(0.013)\end{array}$ & $\begin{array}{c}-0.192^{* * *} \\
(0.021)\end{array}$ & $\begin{array}{c}0.130^{* * *} \\
(0.012)\end{array}$ & $\begin{array}{c}0.109^{* * *} \\
(0.018)\end{array}$ \\
\hline +3 Weeks from Lockdown & $\begin{array}{c}-0.116^{* * *} \\
(0.021)\end{array}$ & $\begin{array}{c}-0.197^{* * *} \\
(0.022)\end{array}$ & $\begin{array}{c}0.105^{* * *} \\
(0.017)\end{array}$ & $\begin{array}{c}0.136^{* * *} \\
(0.015)\end{array}$ \\
\hline +4 Weeks from Lockdown & $\begin{array}{c}-0.194^{* *} \\
(0.049)\end{array}$ & $\begin{array}{c}-0.204^{* * *} \\
(0.030)\end{array}$ & $\begin{array}{c}0.029 \\
(0.023)\end{array}$ & $\begin{array}{c}0.129^{* * *} \\
(0.015)\end{array}$ \\
\hline +5 Weeks from Lockdown & $\begin{array}{l}-0.095^{* *} \\
(0.026)\end{array}$ & $\begin{array}{c}-0.177^{* * *} \\
(0.024)\end{array}$ & $\begin{array}{c}0.101^{* * *} \\
(0.017)\end{array}$ & $\begin{array}{c}0.116^{* * *} \\
(0.016)\end{array}$ \\
\hline +6 Weeks from Lockdown & $\begin{array}{c}-0.078^{* * *} \\
(0.018)\end{array}$ & $\begin{array}{c}-0.168^{* * *} \\
(0.020)\end{array}$ & $\begin{array}{c}0.097^{* * *} \\
(0.014)\end{array}$ & $\begin{array}{c}0.135^{* * *} \\
(0.015)\end{array}$ \\
\hline +7 Weeks from Lockdown & $\begin{array}{l}-0.108^{* *} \\
(0.027)\end{array}$ & $\begin{array}{c}-0.174^{* * *} \\
(0.024)\end{array}$ & $\begin{array}{c}0.058^{* * *} \\
(0.011)\end{array}$ & $\begin{array}{c}0.116^{* * *} \\
(0.014)\end{array}$ \\
\hline +8 Weeks from Lockdown & $\begin{array}{c}-0.072^{* *} \\
(0.019)\end{array}$ & $\begin{array}{c}-0.146^{* * *} \\
(0.022)\end{array}$ & $\begin{array}{c}0.064^{* * *} \\
(0.015)\end{array}$ & $\begin{array}{l}0.105^{* * *} \\
(0.020)\end{array}$ \\
\hline Observations & 1,904 & 1,904 & 1,904 & 1,904 \\
\hline Adjusted $\mathrm{R}^{2}$ & 0.847 & 0.767 & 0.972 & 0.675 \\
\hline Residual Std. Error $(\mathrm{df}=1866)$ & 0.122 & 0.077 & 0.098 & 0.102 \\
\hline
\end{tabular}

${ }^{*} \mathrm{p}<0.05 ;{ }^{* *} \mathrm{p}<0.01 ;{ }^{* * *} \mathrm{p}<0.001$

Note: Regressions include MSA fixed-effects and weekday controls. Standard errors are clustered at the MSA-level. 
Table 3: Email Regression Results Over Time

\begin{tabular}{|c|c|c|c|c|c|c|}
\hline & \multicolumn{6}{|c|}{ Dependent variable: } \\
\hline & $\begin{array}{c}\text { Emails Sent } \\
\text { Distinct (log) } \\
(1)\end{array}$ & $\begin{array}{c}\text { Emails Sent } \\
\text { Internal (log) } \\
(2)\end{array}$ & $\begin{array}{c}\text { Emails Sent } \\
\text { External (log) } \\
\text { (3) }\end{array}$ & $\begin{array}{l}\text { Email } \\
\text { Recipients } \\
(\log ) \\
(4)\end{array}$ & $\begin{array}{c}\text { Workday Span } \\
\text { (log) } \\
(5)\end{array}$ & $\begin{array}{c}\text { Emails Sent } \\
\text { After Hours } \\
\text { (log) } \\
(6)\end{array}$ \\
\hline -8 Weeks from Lockdown & $\begin{array}{l}-0.048^{* *} \\
(0.013)\end{array}$ & $\begin{array}{c}-0.099^{* * *} \\
(0.020)\end{array}$ & $\begin{array}{l}-0.066^{* *} \\
(0.019)\end{array}$ & $\begin{array}{c}-0.076^{* * *} \\
(0.014)\end{array}$ & $\begin{array}{c}-0.021^{* * *} \\
(0.004)\end{array}$ & $\begin{array}{c}-0.178^{* * *} \\
(0.026)\end{array}$ \\
\hline -7 Weeks from Lockdown & $\begin{array}{l}-0.044^{*} \\
(0.016)\end{array}$ & $\begin{array}{c}-0.092^{* * *} \\
(0.020)\end{array}$ & $\begin{array}{l}-0.074^{* *} \\
(0.020)\end{array}$ & $\begin{array}{c}-0.062^{* *} \\
(0.015)\end{array}$ & $\begin{array}{c}-0.028^{* * *} \\
(0.004)\end{array}$ & $\begin{array}{c}-0.172^{* * *} \\
(0.030)\end{array}$ \\
\hline -6 Weeks from Lockdown & $\begin{array}{l}-0.043^{*} \\
(0.015)\end{array}$ & $\begin{array}{c}-0.092^{* * *} \\
(0.021)\end{array}$ & $\begin{array}{l}-0.066^{*} \\
(0.026)\end{array}$ & $\begin{array}{c}-0.065^{* * *} \\
(0.015)\end{array}$ & $\begin{array}{c}-0.019^{* * *} \\
(0.003)\end{array}$ & $\begin{array}{c}-0.156^{* * *} \\
(0.032)\end{array}$ \\
\hline-5 Weeks from Lockdown & $\begin{array}{l}-0.036 \\
(0.022)\end{array}$ & $\begin{array}{l}-0.089^{* *} \\
(0.027)\end{array}$ & $\begin{array}{l}-0.050^{* *} \\
(0.017)\end{array}$ & $\begin{array}{c}-0.073^{* * *} \\
(0.014)\end{array}$ & $\begin{array}{c}-0.021^{* * *} \\
(0.005)\end{array}$ & $\begin{array}{l}-0.136^{* *} \\
(0.035)\end{array}$ \\
\hline -4 Weeks from Lockdown & $\begin{array}{c}-0.042^{* *} \\
(0.012)\end{array}$ & $\begin{array}{c}-0.093^{* * *} \\
(0.019)\end{array}$ & $\begin{array}{l}-0.046^{*} \\
(0.017)\end{array}$ & $\begin{array}{c}-0.061^{* * *} \\
(0.013)\end{array}$ & $\begin{array}{c}-0.018^{* * *} \\
(0.002)\end{array}$ & $\begin{array}{c}-0.151^{* * *} \\
(0.029)\end{array}$ \\
\hline -3 Weeks from Lockdown & $\begin{array}{c}-0.038^{* *} \\
(0.012)\end{array}$ & $\begin{array}{c}-0.091^{* * *} \\
(0.018)\end{array}$ & $\begin{array}{l}-0.022 \\
(0.013)\end{array}$ & $\begin{array}{c}-0.053^{* *} \\
(0.013)\end{array}$ & $\begin{array}{c}-0.018^{* * *} \\
(0.004)\end{array}$ & $\begin{array}{c}-0.149^{* * *} \\
(0.025)\end{array}$ \\
\hline-2 Weeks from Lockdown & $\begin{array}{l}-0.025^{*} \\
(0.010)\end{array}$ & $\begin{array}{l}-0.051^{* *} \\
(0.017)\end{array}$ & $\begin{array}{c}-0.022 \\
(0.012)\end{array}$ & $\begin{array}{l}-0.016 \\
(0.015)\end{array}$ & $\begin{array}{l}-0.009^{*} \\
(0.003)\end{array}$ & $\begin{array}{l}-0.093^{* *} \\
(0.024)\end{array}$ \\
\hline Lockdown Week & $\begin{array}{c}0.074^{* * *} \\
(0.013)\end{array}$ & $\begin{array}{c}0.126^{* * *} \\
(0.020)\end{array}$ & $\begin{array}{l}0.033^{*} \\
(0.015)\end{array}$ & $\begin{array}{l}0.062^{* *} \\
(0.018)\end{array}$ & $\begin{array}{c}0.040^{* * *} \\
(0.005)\end{array}$ & $\begin{array}{c}0.076 \\
(0.037)\end{array}$ \\
\hline +1 Week from Lockdown & $\begin{array}{c}0.087^{* * *} \\
(0.015)\end{array}$ & $\begin{array}{c}0.114^{* * *} \\
(0.023)\end{array}$ & $\begin{array}{c}0.010 \\
(0.013)\end{array}$ & $\begin{array}{c}-0.008 \\
(0.016)\end{array}$ & $\begin{array}{c}0.083^{* * *} \\
(0.006)\end{array}$ & $\begin{array}{c}0.056 \\
(0.038)\end{array}$ \\
\hline +2 Weeks from Lockdown & $\begin{array}{c}0.050^{*} \\
(0.023)\end{array}$ & $\begin{array}{c}0.065^{*} \\
(0.029)\end{array}$ & $\begin{array}{c}-0.024 \\
(0.017)\end{array}$ & $\begin{array}{l}-0.016 \\
(0.014)\end{array}$ & $\begin{array}{c}0.092^{* * *} \\
(0.006)\end{array}$ & $\begin{array}{c}0.045 \\
(0.044)\end{array}$ \\
\hline +3 Weeks from Lockdown & $\begin{array}{c}0.001 \\
(0.020)\end{array}$ & $\begin{array}{c}0.006 \\
(0.028)\end{array}$ & $\begin{array}{c}-0.059^{* * *} \\
(0.014)\end{array}$ & $\begin{array}{l}-0.019 \\
(0.017)\end{array}$ & $\begin{array}{c}0.079^{* * *} \\
(0.009)\end{array}$ & $\begin{array}{l}-0.025 \\
(0.053)\end{array}$ \\
\hline +4 Weeks from Lockdown & $\begin{array}{l}-0.101^{*} \\
(0.035)\end{array}$ & $\begin{array}{l}-0.104^{* *} \\
(0.035)\end{array}$ & $\begin{array}{c}-0.117^{* * *} \\
(0.026)\end{array}$ & $\begin{array}{l}-0.006 \\
(0.027)\end{array}$ & $\begin{array}{l}0.044^{* *} \\
(0.012)\end{array}$ & $\begin{array}{l}-0.082^{*} \\
(0.038)\end{array}$ \\
\hline +5 Weeks from Lockdown & $\begin{array}{c}-0.032 \\
(0.024)\end{array}$ & $\begin{array}{c}-0.038 \\
(0.029)\end{array}$ & $\begin{array}{c}-0.065^{* *} \\
(0.017)\end{array}$ & $\begin{array}{l}-0.008 \\
(0.026)\end{array}$ & $\begin{array}{c}0.069^{* * *} \\
(0.010)\end{array}$ & $\begin{array}{l}-0.075 \\
(0.045)\end{array}$ \\
\hline +6 Weeks from Lockdown & $\begin{array}{l}-0.029 \\
(0.021)\end{array}$ & $\begin{array}{l}-0.059^{*} \\
(0.027)\end{array}$ & $\begin{array}{c}-0.074^{* *} \\
(0.018)\end{array}$ & $\begin{array}{l}-0.029 \\
(0.015)\end{array}$ & $\begin{array}{c}0.061^{* * *} \\
(0.009)\end{array}$ & $\begin{array}{l}-0.083 \\
(0.045)\end{array}$ \\
\hline +7 Weeks from Lockdown & $\begin{array}{l}-0.047^{*} \\
(0.016)\end{array}$ & $\begin{array}{c}-0.089^{* * *} \\
(0.021)\end{array}$ & $\begin{array}{c}-0.092^{* * *} \\
(0.014)\end{array}$ & $\begin{array}{l}-0.015 \\
(0.016)\end{array}$ & $\begin{array}{c}0.049^{* * *} \\
(0.007)\end{array}$ & $\begin{array}{l}-0.085^{*} \\
(0.039)\end{array}$ \\
\hline +8 Weeks from Lockdown & $\begin{array}{l}-0.021 \\
(0.018)\end{array}$ & $\begin{array}{l}-0.067^{*} \\
(0.026)\end{array}$ & $\begin{array}{c}-0.066^{* *} \\
(0.021)\end{array}$ & $\begin{array}{c}-0.034 \\
(0.019)\end{array}$ & $\begin{array}{c}0.048^{* * *} \\
(0.009)\end{array}$ & $\begin{array}{l}-0.086 \\
(0.041)\end{array}$ \\
\hline Observations & 1,904 & 1,904 & 1,904 & 1,904 & 1,904 & 1,904 \\
\hline Adjusted $\mathrm{R}^{2}$ & 0.930 & 0.953 & 0.952 & 0.727 & 0.939 & 0.965 \\
\hline Residual Std. Error $(\mathrm{df}=1866)$ & 0.140 & 0.152 & 0.137 & 0.104 & 0.061 & 0.137 \\
\hline
\end{tabular}

${ }^{*} \mathrm{p}<0.05 ;{ }^{* *} \mathrm{p}<0.01 ;{ }^{* * *} \mathrm{p}<0.001$

Note: Regressions include MSA fixed-effects and weekday controls. Standard errors are clustered at the MSA-level. 


\section{References}

Bloom, N., Liang, J., Roberts, J., \& Ying, Z. J. (2015). Does Working from Home Work? Evidence from a Chinese Experiment. The Quarterly Journal of Economics, 130(1), 165-218. https://doi.org/10.3386/w18871

Choudhury, P., Foroughi, C., \& Larson, B. (2019). Work-from-anywhere: The Productivity Effects of Geographic Flexibility. SSRN Electronic Journal. https://doi.org/10.2139/ssrn.3494473

Impink, S. M., Prat, A., \& Sadun, R. (2020). Measuring Collaboration in Modern Organizations. AEA Papers and Proceedings, 110, 181-186. https://doi.org/10.1257/pandp.20201068

Kleinbaum, A. M., Stuart, T. E., \& Tushman, M. L. (2013). Discretion Within Constraint: Homophily and Structure in a Formal Organization. Organization Science, 24(5), 1316-1336. https://doi.org/10.1287/orsc.1120.0804

Polzer, J. T., DeFilippis, E., \& Tobio, K. (2018). Countries, Culture, and Collaboration. Academy of Management Proceedings, 2018(1), 17645. https://doi.org/10.5465/AMBPP.2018.17645abstract

Raghuram, Sumita and Hill, N Sharon and Gibbs, Jennifer L and Maruping, Likoebe M (2019). Virtual Work: Bridging Research Clusters. Academy of Management Annals, 13(1), 308-341.

https://journals-aom-org.ezp-prod1.hul.harvard.edu/doi/10.5465/annals.2017.0020

Srivastava, S. B., Goldberg, A., Manian, V. G., \& Potts, C. (2017). Enculturation Trajectories: Language, Cultural Adaptation, and Individual Outcomes in Organizations. Management Science, 64(3), 1348-1364. https://doi.org/10.1287/mnsc.2016.2671

Wasson, C. (2004). Multitasking during virtual meetings. Human Resource Planning, 27(4), 47-61.

Wiesenfeld, B. M., Raghuram, S., \& Garud, R. (1999). Communication Patterns as Determinants of Organizational Identification in a Virtual Organization. Organization Science, 10(6), 777-790. JSTOR. 


\section{Appendix}

\section{Section 1: Data and Variable Descriptions}

\section{Data Description}

Our dataset consists of de-identified email and meeting meta-data acquired from an information technology services provider. The user-level data was aggregated to the MSA-day level, and represents the activity of 3,143,270 users across 21,478 firms in 16 large metropolitan areas.

\section{Variable Description}

\section{Meeting Variables}

1. Meeting Hours- The average daily number of hours an individual spends in meetings. This variable is calculated by taking the daily hours each user spends in meetings and calculating the average across users for a given MSA.

2. Meeting Count- The average daily number of meetings an individual attends. This variable is calculated by taking the daily number of meetings each user attends and calculating the average across users for a given MSA.

3. Meeting Attendees- The average number of people that attend each meeting. This variable is calculated by taking the attendance count for each meeting and calculating the average across meetings for a given MSA day.

4. Meeting Length- The average length of time a meeting runs for. This variable is calculated by taking the duration for each meeting and calculating the average across meetings for a given MSA day.

5. Online Meetings- The average daily number of online meetings an individual attends, where a meeting is designated online if it has a virtual meeting link from the provider's service included in the meeting invite. This variable is calculated by taking the daily number of online meetings each user attends and calculating the average across users for a given MSA.

6. Multi-Country Meeting Count- The total number of multi-country meetings for a given MSA day, where a meeting is designated multi-country if the locations logged for users on the meeting invite were from at least two different countries. This variable is calculated by taking the sum of the daily number of multi-country meetings across all users in a given MSA.

\section{Email Variables}

1. Internal Emails Sent- The average daily number of emails received by internal recipients from internal senders, such that a single email sent to two separate recipients would count as two internal emails, rather than one email. The sender and the receiver must have the same email domain (i.e. “@company.com”). This variable is calculated by taking the daily number of emails sent to internal users and calculating the average across users for a given MSA.

2. External Emails Sent- The average daily number of emails received by external recipients from internal senders, such that a single email sent to two separate recipients would count as two external emails, rather than one email. The sender and the receiver must have different email domains (i.e. “@company1.com” and “@company2.com”). This variable is calculated by taking the daily number of emails sent to external constituents and calculating the average across users for a given MSA.

3. Distinct Emails Sent- The average daily number of emails sent from a single user. A single email sent to multiple internal and/or external constituents is only counted once for the distinct email variable. This variable is calculated by taking the daily number of emails sent from a single user and calculating the average across users for a given MSA. 
4. Email Recipients- The average number of recipients included on email messages. This variable is calculated by taking the number of people that were included (whether To, CC'ed or BCC'ed) on each email and calculating the average across messages for a given MSA.

5. Workday Span- The average daily number of hours in between the first and last email sent or meeting attended by an individual in a 24-hour day block. The 24-hour day block is determined by 12am-11:59pm in the user's local time zone. This variable is calculated by taking the number of hours in between the first and last meeting or email for each user's 24-hour block and then calculating the average across users for a given MSA.

6. After Hours Emails- The average daily number of emails received outside of the hours of 8am $6 \mathrm{pm}$ on Monday -Friday or on the weekends by individuals (internal or external) from a single user. This variable is calculated by taking the total number of emails received from a single user outside of 'working hours' and calculating the average across users for a given MSA. 
Section 2: Tables, provides tables with supporting and additional results.

Table S1: Summary Statistics for Meeting and Email Variables

\begin{tabular}{lcccccc}
\hline & \multicolumn{2}{c}{ Mean } & \multicolumn{2}{c}{ Std. Dev } & \multicolumn{2}{c}{ \# of Obs } \\
\cline { 2 - 7 } Variable & Pre-lockdown & $\begin{array}{c}\text { Post- } \\
\text { lockdown }\end{array}$ & $\begin{array}{c}\text { Pre- } \\
\text { lockdown }\end{array}$ & $\begin{array}{c}\text { Post- } \\
\text { lockdown }\end{array}$ & Pre-lockdown & $\begin{array}{c}\text { Post- } \\
\text { lockdown }\end{array}$ \\
\hline Meeting Hours & 2.693 & 2.451 & 0.636 & 0.725 & 944 & 944 \\
Meeting Count & 5.884 & 6.877 & 4.154 & 5.232 & 944 & 944 \\
Meeting Attendees & 15.614 & 17.743 & 2.634 & 3.051 & 944 & 944 \\
Meeting Length & 1.006 & 0.796 & 0.158 & 0.061 & 944 & 944 \\
Workday Span & 9.837 & 10.670 & 2.301 & 2.336 & 944 & 944 \\
Emails Sent Internal & 27.145 & 29.337 & 19.873 & 21.500 & 944 & 944 \\
Emails Sent External & 8.388 & 8.156 & 5.922 & 5.470 & 944 & 944 \\
Emails Sent Distinct & 9.666 & 10.086 & 3.810 & 4.133 & 944 & 944 \\
Email Recipients & 8.531 & 8.782 & 1.840 & 1.877 & 944 & 944 \\
Emails Sent After Hours & 7.637 & 8.043 & 6.876 & 6.778 & 944 & 944 \\
\hline
\end{tabular}

Table S2: Regression Results for Meeting and Email Variables

\begin{tabular}{lcccccc}
\hline Variable & $\begin{array}{c}\text { Pre- } \\
\text { Lockdown } \\
\text { Mean }\end{array}$ & $\begin{array}{c}\text { Log } \\
\text { Coefficient }\end{array}$ & P-Value & \% Change [CI] & $\begin{array}{c}\text { \% Change * } \\
\text { Pre- } \\
\text { Lockdown } \\
\text { Mean }\end{array}$ & \# of Obs \\
\hline Meeting Hours & 2.693 & -0.122 & $<0.001$ & $-11.519[-14.29,-8.659]$ & -0.310 & 1,904 \\
Meeting Count & 5.884 & 0.122 & $<0.001$ & $12.922[11.448,14.415]$ & 0.760 & 1,904 \\
Meeting Attendees & 15.614 & 0.127 & $<0.001$ & $13.505[10.611,16.475]$ & 2.109 & 1,904 \\
Meeting Length & 1.006 & -0.225 & $<0.001$ & $-20.128[-23.042,-17.103]$ & -0.203 & 1,904 \\
Workday Span & 9.837 & 0.079 & $<0.001$ & $8.219[7.142,9.306]$ & 0.809 & 1,904 \\
Emails Sent Distinct & 9.666 & 0.023 & 0.09 & $2.349[-0.188,4.95]$ & 0.227 & 1,904 \\
Emails Sent Internal & 27.145 & 0.051 & $<0.001$ & $5.272[2.977,7.619]$ & 1.431 & 1,904 \\
Emails Sent External & 8.388 & -0.017 & 0.116 & $-1.698[-3.656,0.3]$ & -0.142 & 1,904 \\
Email Recipients & 8.531 & 0.029 & 0.043 & $2.901[0.329,5.538]$ & 0.247 & 1,904 \\
Emails Sent After & 7.637 & 0.079 & 0.001 & $8.262[4.016,12.681]$ & 0.631 & 1,904 \\
Hours & & & & & & \\
\hline
\end{tabular}

Regressions include MSA fixed-effects and weekday controls. Standard errors are clustered at the MSA-level. 
Table S3: Robustness Check: Regression Results, User Count Weighted

\begin{tabular}{lcccccc}
\hline Variable & $\begin{array}{c}\text { Pre- } \\
\text { Lockdown } \\
\text { Mean }\end{array}$ & $\begin{array}{c}\text { Log } \\
\text { Coeffici } \\
\text { ent }\end{array}$ & P-Value & \% Change [CI] & $\begin{array}{c}\text { \% Change * } \\
\text { Pre-Lockdown } \\
\text { Mean }\end{array}$ & $\begin{array}{c}\text { \# of } \\
\text { Obs }\end{array}$ \\
\hline Meeting Hours & 2.693 & -0.058 & $<0.001$ & $-5.621[-7.933,-3.25]$ & -0.151 & 1,904 \\
Meeting Count & 5.884 & 0.132 & $<0.001$ & $14.075[11.99,16.198]$ & 0.828 & 1,904 \\
Meeting Attendees & 15.614 & 0.126 & $<0.001$ & $13.466[9.995,17.046]$ & 2.103 & 1,904 \\
Meeting Length & 1.006 & -0.176 & $<0.001$ & $-16.173[-18.949,-13.3]$ & -0.163 & 1,904 \\
Workday Span & 9.837 & 0.069 & $<0.001$ & $7.16[6.104,8.228]$ & 0.704 & 1,904 \\
Emails Sent Distinct & 9.666 & 0.036 & 0.037 & $3.656[0.522,6.888]$ & 0.353 & 1,904 \\
Emails Sent Internal & 27.145 & 0.071 & $<0.001$ & $7.365[4.88,9.908]$ & 1.999 & 1,904 \\
Emails Sent External & 8.388 & -0.029 & 0.017 & $-2.889[-4.939,-0.794]$ & -0.242 & 1,904 \\
Email Recipients & 8.531 & 0.019 & 0.144 & $1.868[-0.504,4.296]$ & 0.159 & 1,904 \\
Emails Sent After Hours & 7.637 & 0.054 & 0.009 & $5.52[1.875,9.295]$ & 0.422 & 1,904 \\
\hline
\end{tabular}

Regressions include MSA fixed-effects and weekday controls. Standard errors are clustered at the MSA-level.

Table S4: Supplemental Regression Results for Online and Multi-Country Meetings

\begin{tabular}{lcccccc}
\hline Variable & $\begin{array}{c}\text { Pre- } \\
\text { Lockdown } \\
\text { Mean }\end{array}$ & $\begin{array}{c}\text { Log } \\
\text { Coefficient }\end{array}$ & $\begin{array}{c}\text { P- } \\
\text { Value }\end{array}$ & \% Change [CI] & $\begin{array}{c}\text { \% Change * } \\
\text { Pre-Lockdown } \\
\text { Mean }\end{array}$ & $\begin{array}{c}\text { \# of } \\
\text { Obs }\end{array}$ \\
\hline $\begin{array}{l}\text { Online Meetings } \\
\begin{array}{l}\text { Multi-Country Meeting } \\
\text { Count }\end{array}\end{array}$ & 0.973 & 0.217 & $<0.001$ & $24.246[14.809,34.459]$ & 0.236 & 1,904 \\
\hline
\end{tabular}

Regressions include MSA fixed-effects and weekday controls. Standard errors are clustered at the MSA-level. 


\section{Section 3: Figures, expands the results section of the main document with additional figures.}

Figure S1: Count of Meeting Users. Represents the total count of users whose meeting activity is included in our MSA-level data on a given day. A user is only counted towards our aggregated MSA total if they are active on a day, implying they have attended at least one meeting.

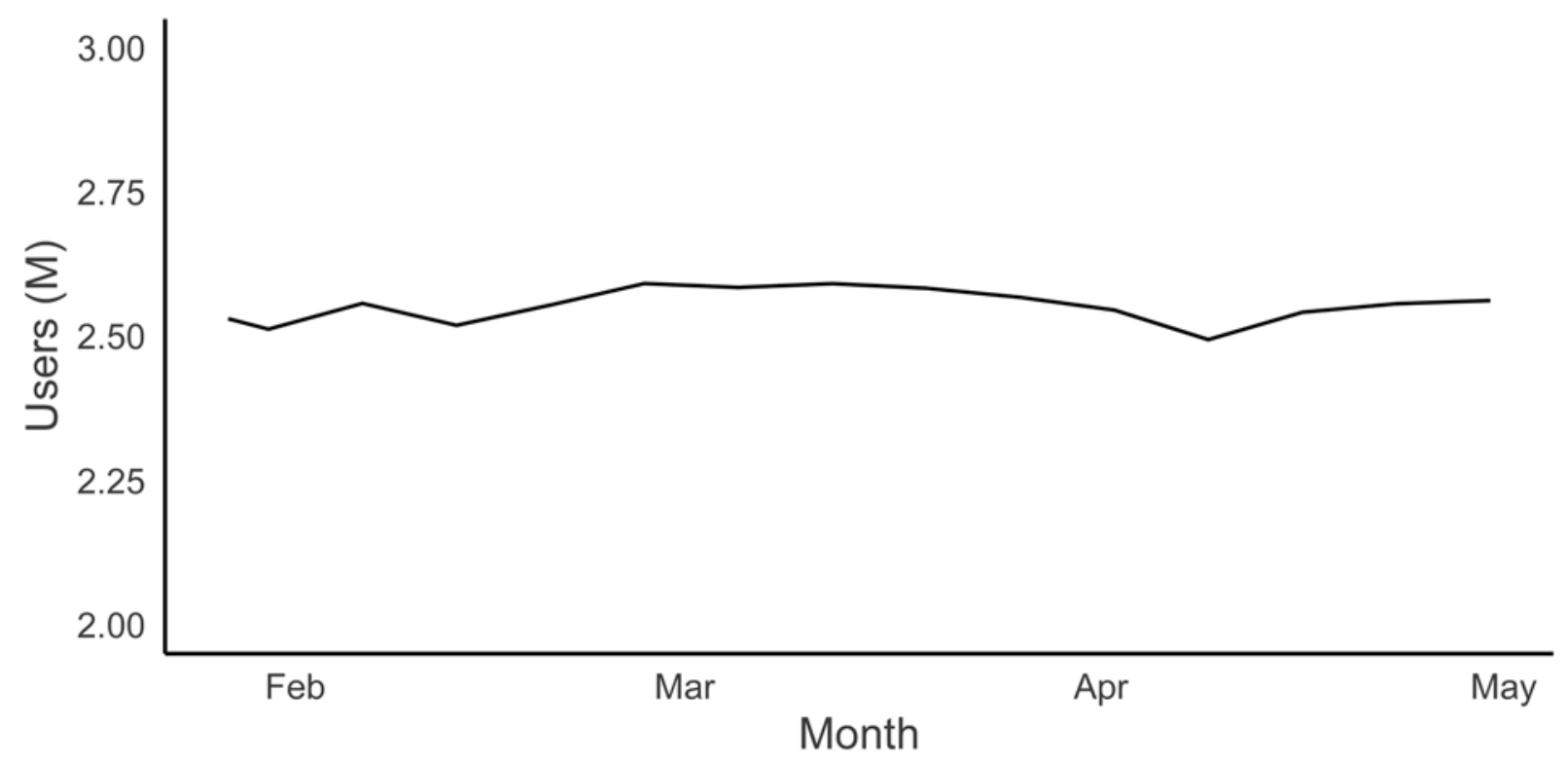

Figure S2: Count of Email User. Represents the total count of users whose email activity is included in our MSA-level data on a given day. A user is only counted towards our aggregated MSA total if they are active on a day, implying they sent at least one email.

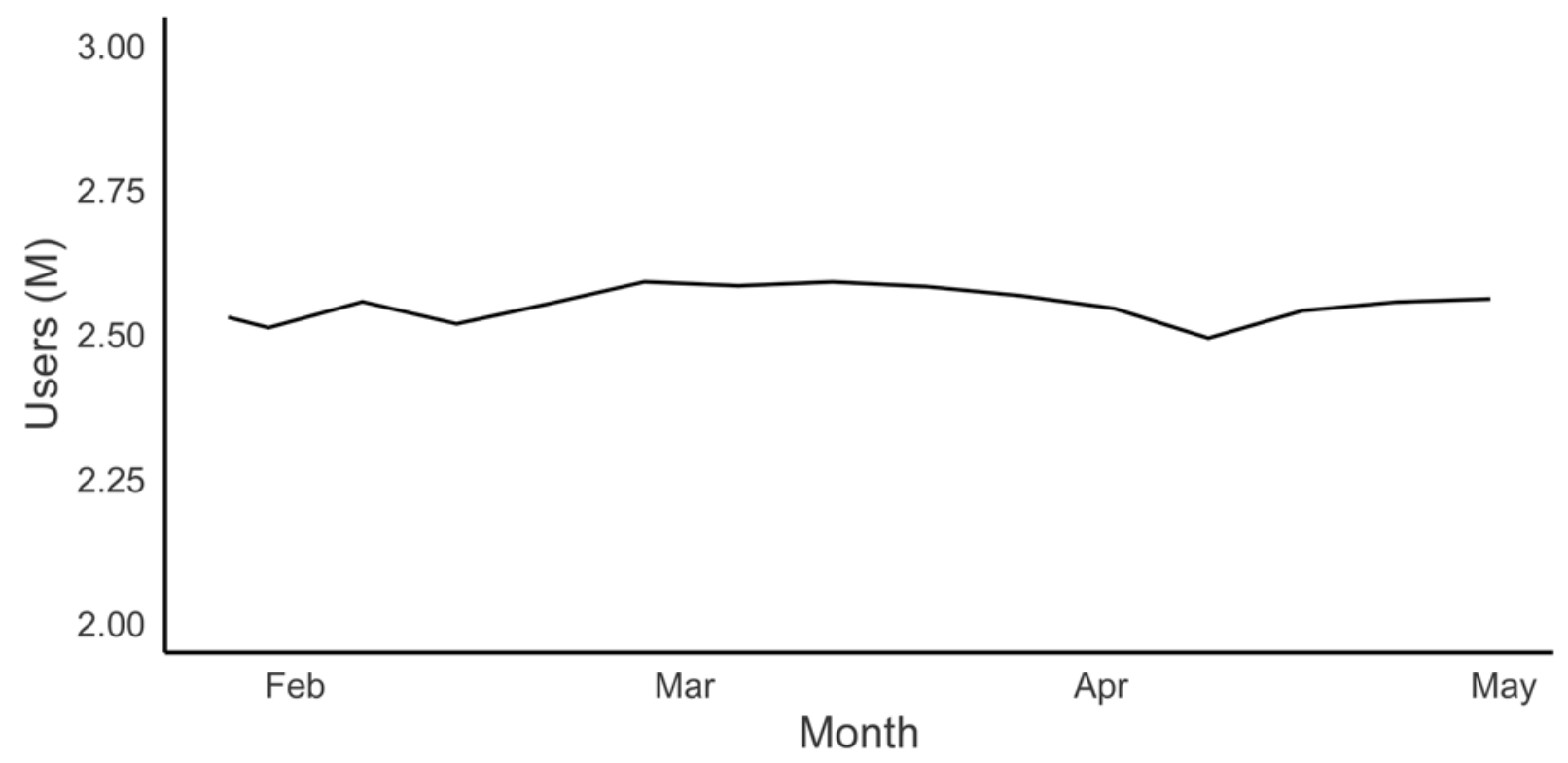


Figure S3: Impact of COVID-19 Lockdown on Supplementary Meeting Data

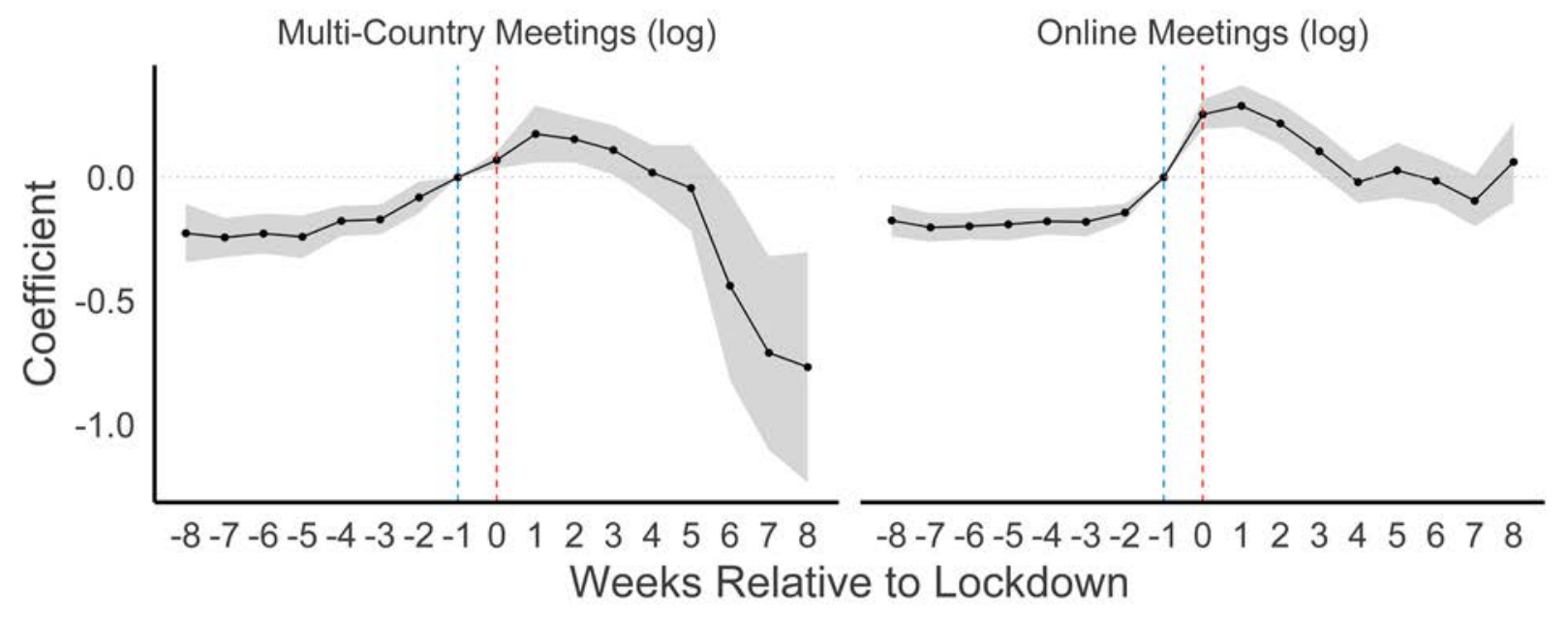

Base Week ; Lockdown Date 
Figure S4: Meetings Robustness Check: Reference Week is 8 Weeks Before Lockdown

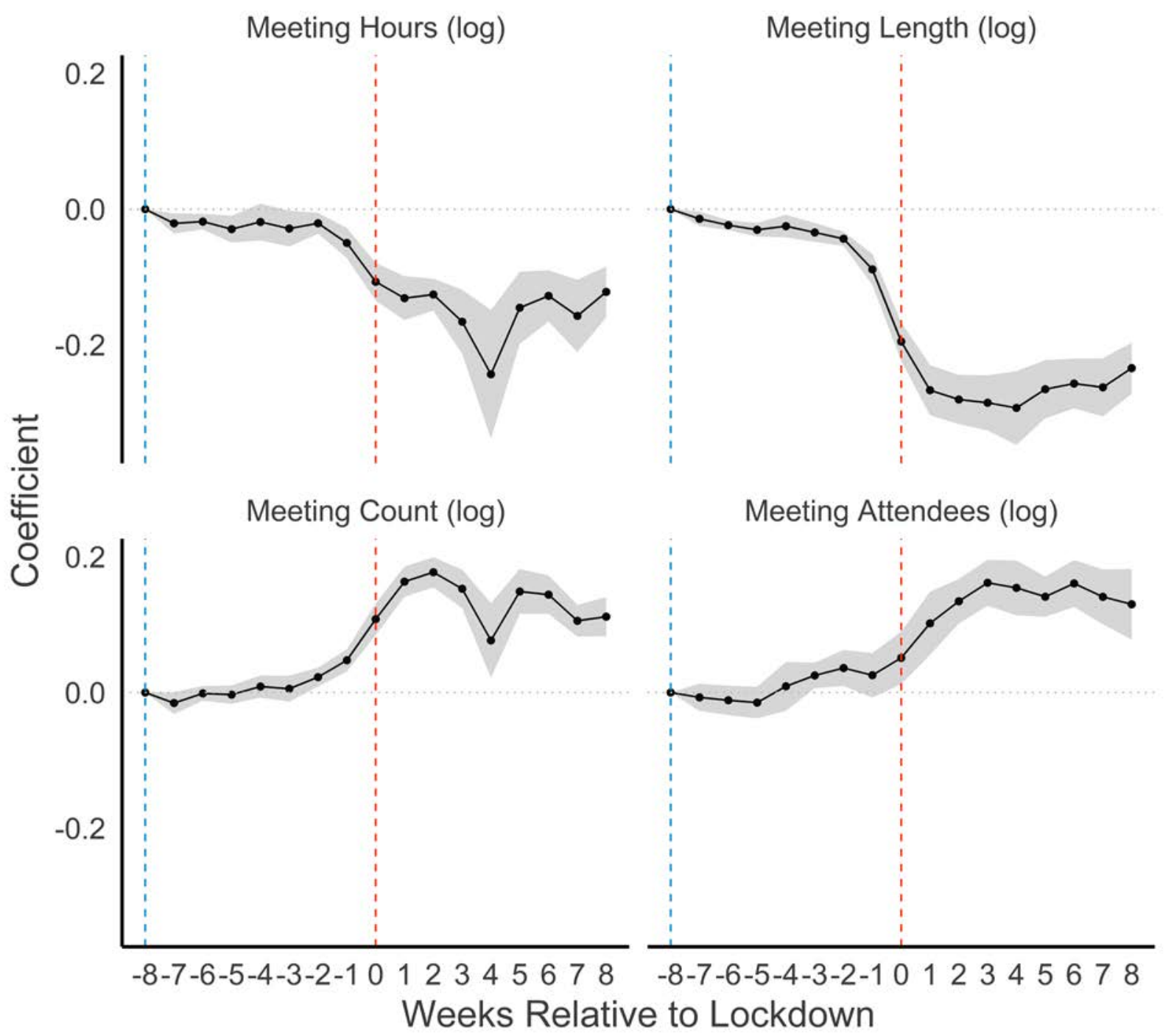

Base Week i Lockdown Date 
Figure S5: Emails Robustness Check: Reference Week is 8 Weeks Before Lockdown
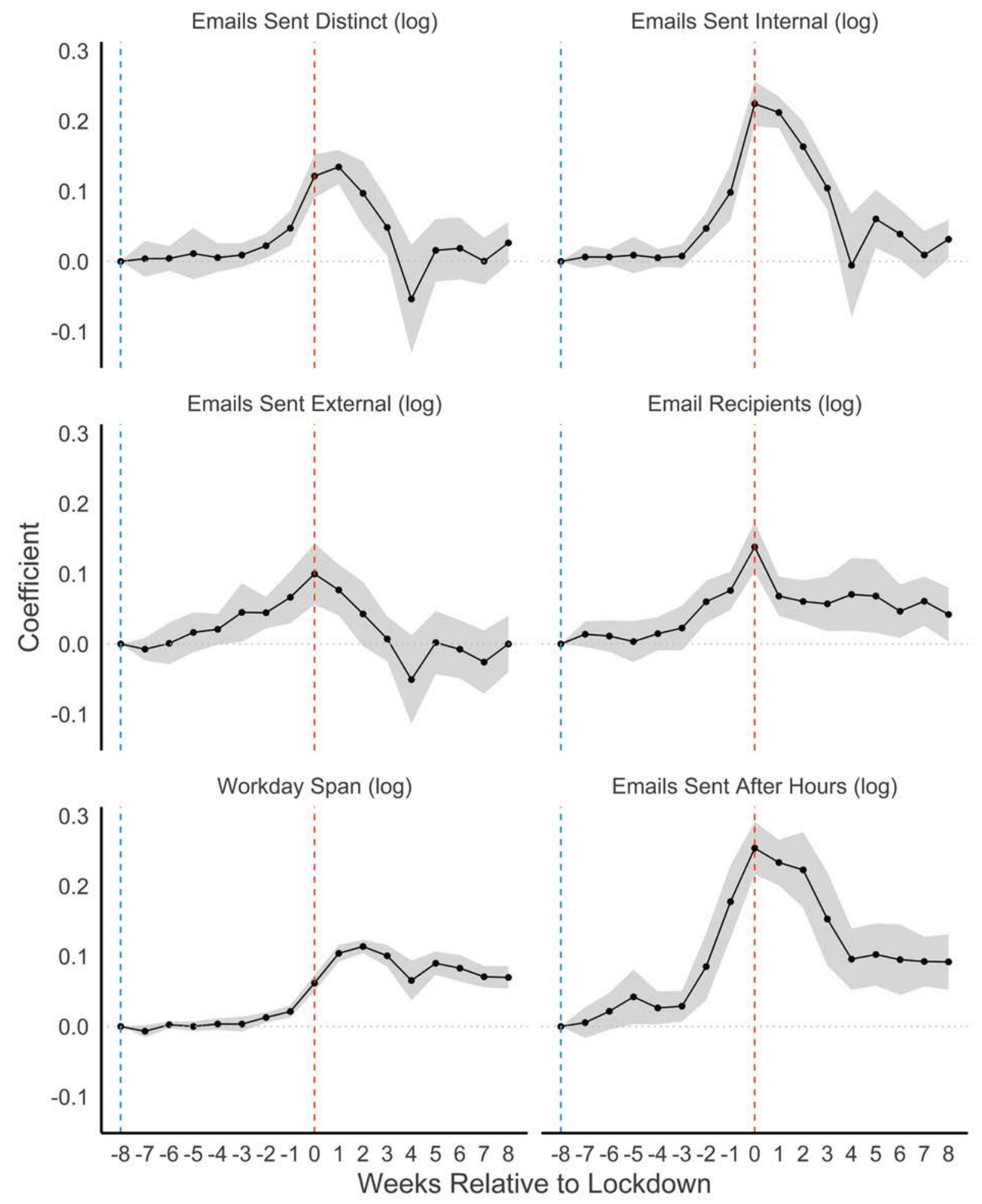

Base Week i Lockdown Date 
Figure S6: Impact of COVID-19 Lockdown on Meeting Hours (log) by MSA
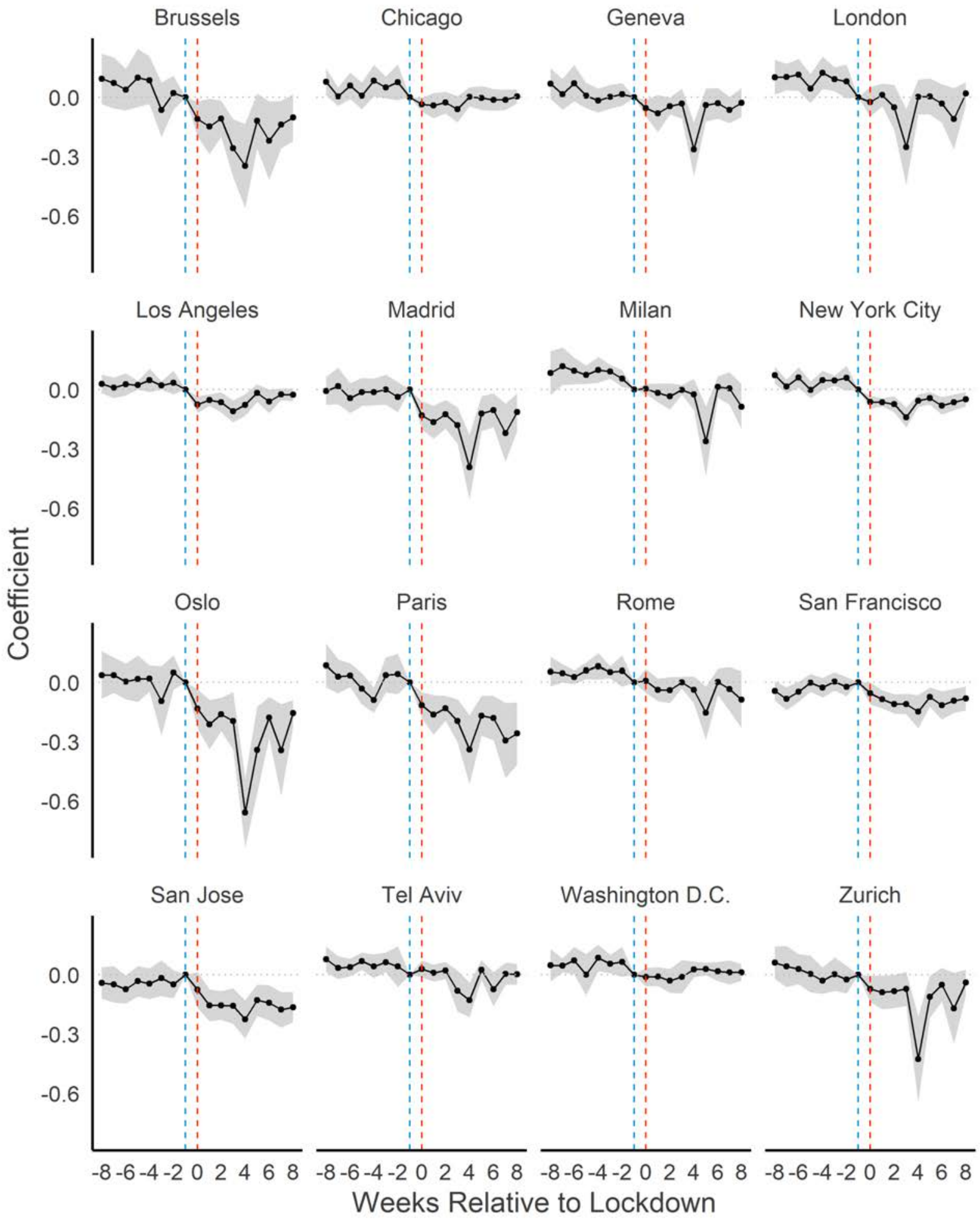

Base Week $\quad$ Lockdown Date 
Figure S7: Impact of COVID-19 Lockdown on Meeting Count (log) by MSA
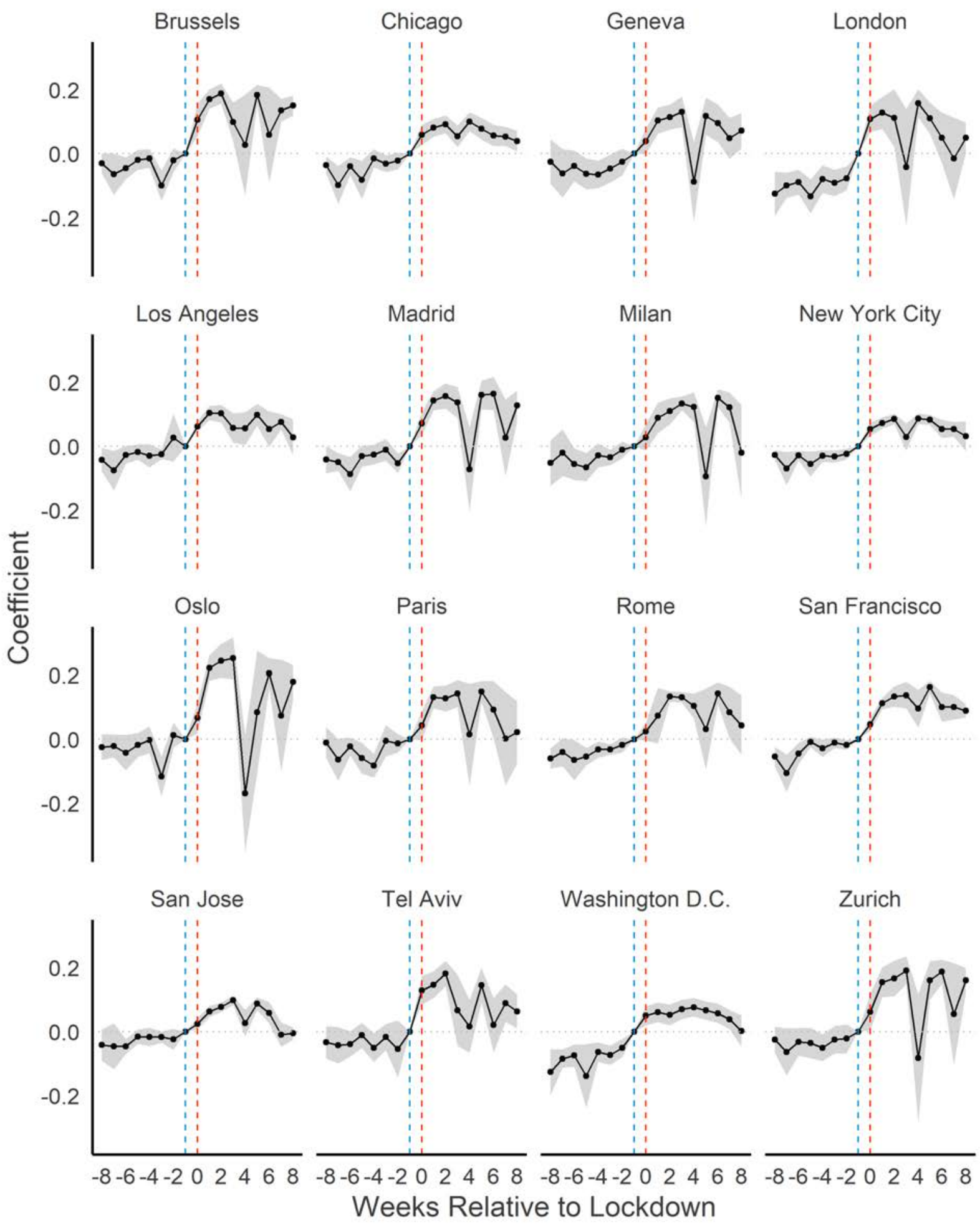

Base Week $\quad$ Lockdown Date 
Figure S8: Impact of COVID-19 Lockdown on Meeting Attendees (log) by MSA

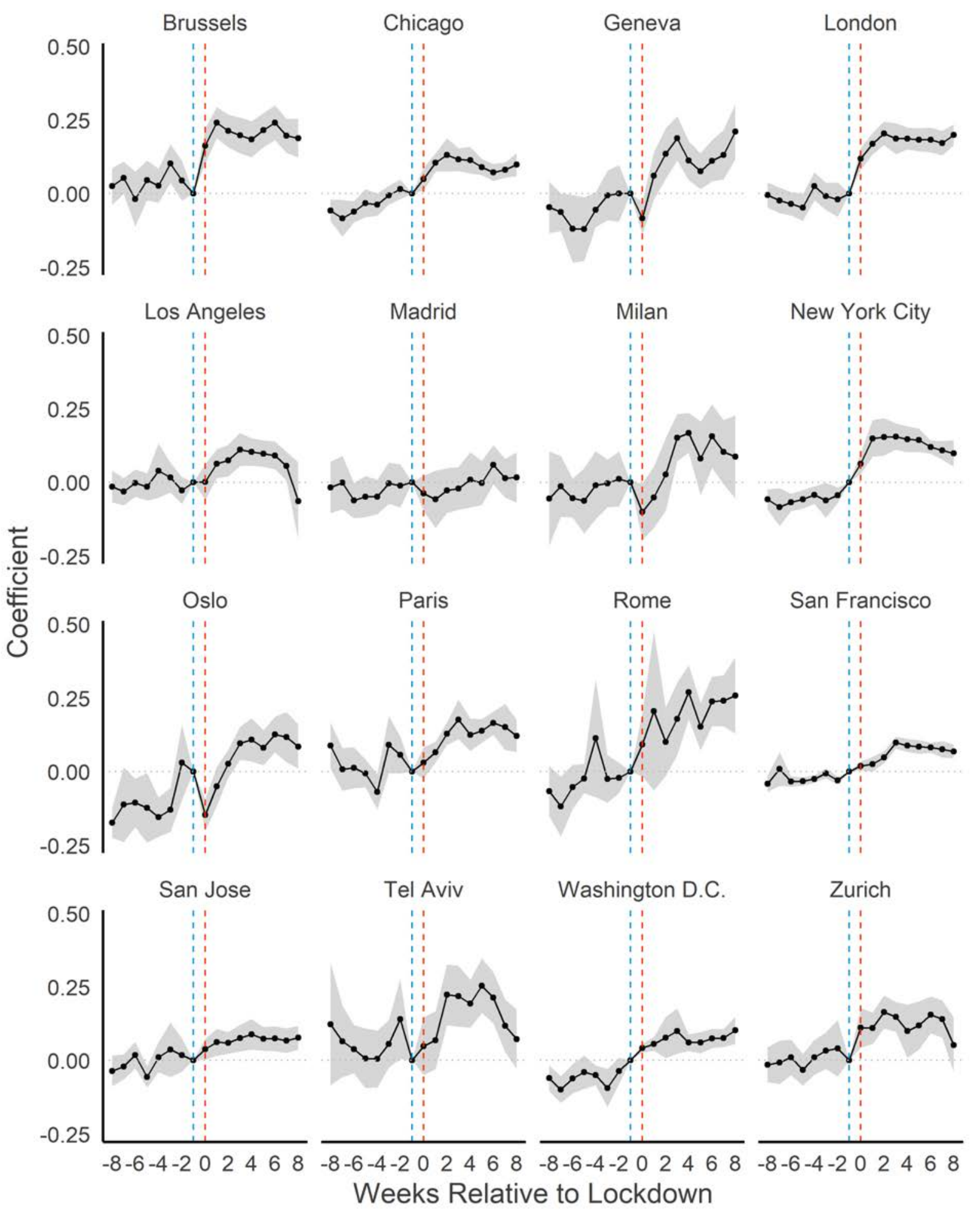

Base Week : Lockdown Date 
Figure S9: Impact of COVID-19 Lockdown on Meeting Length (log) by MSA
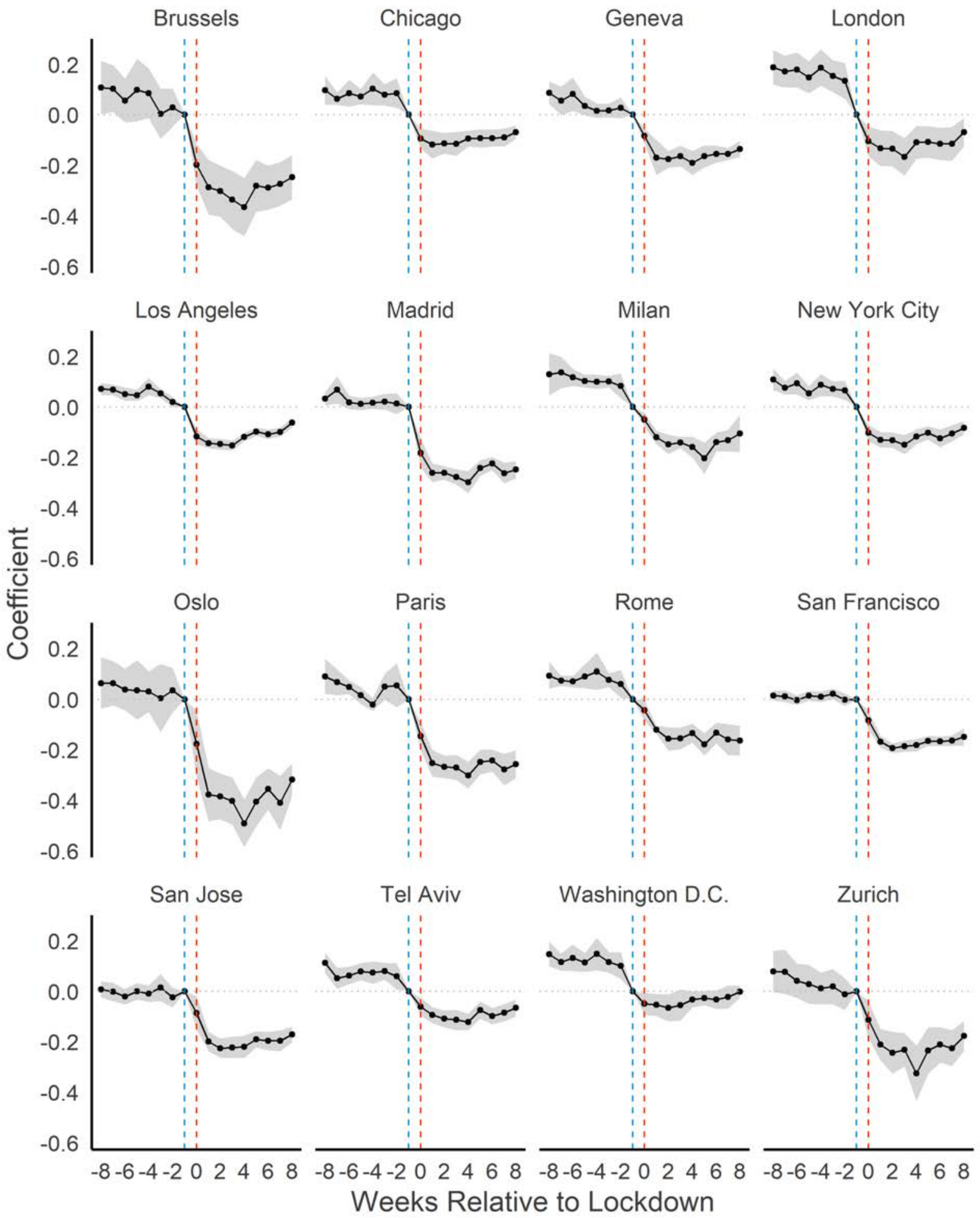

Base Week i Lockdown Date 
Figure S10: Impact of COVID-19 Lockdown on Emails Sent Internal (log) by MSA
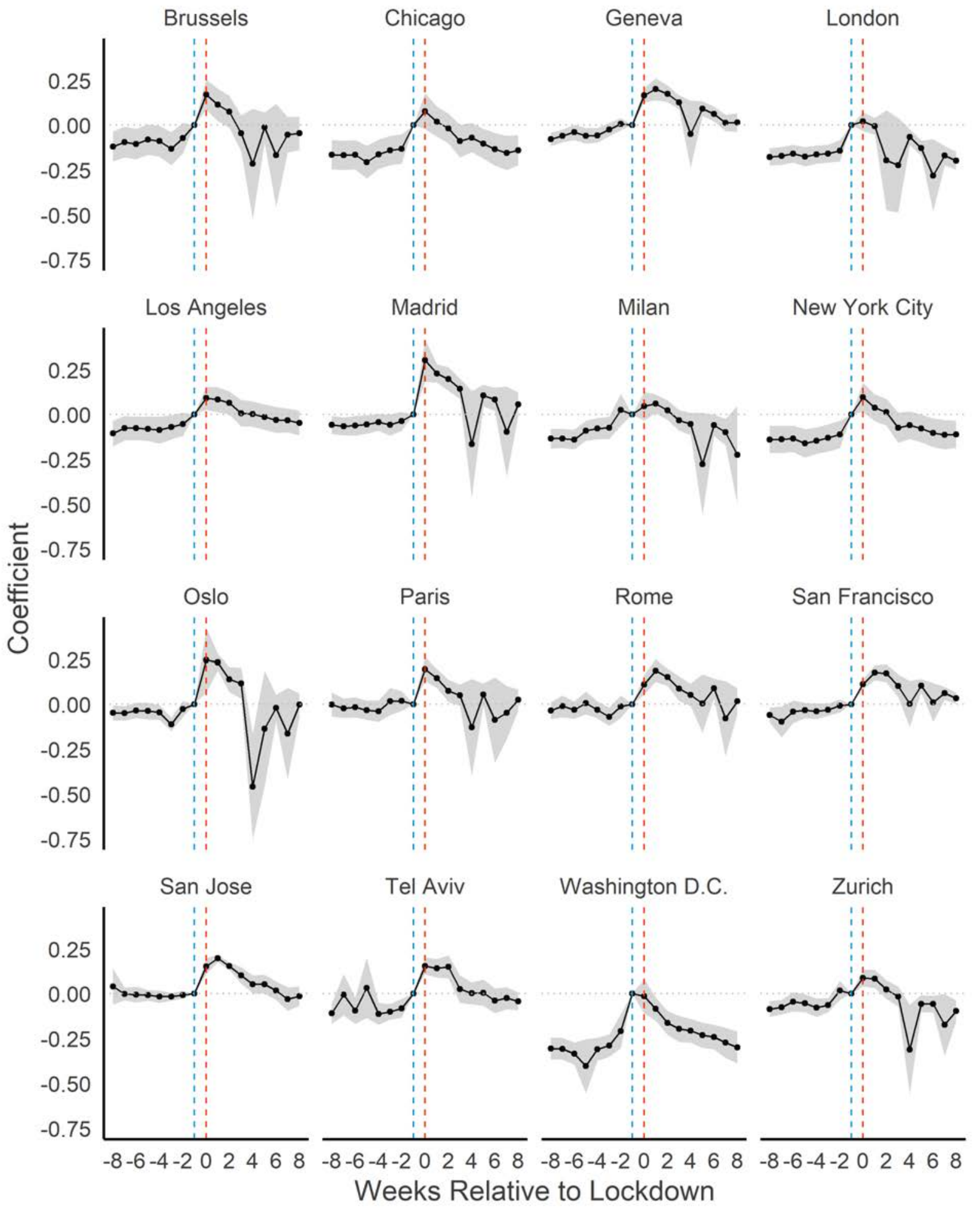

Base Week Lockdown Date 
Figure S11: Impact of COVID-19 Lockdown on Emails Sent External (log) by MSA

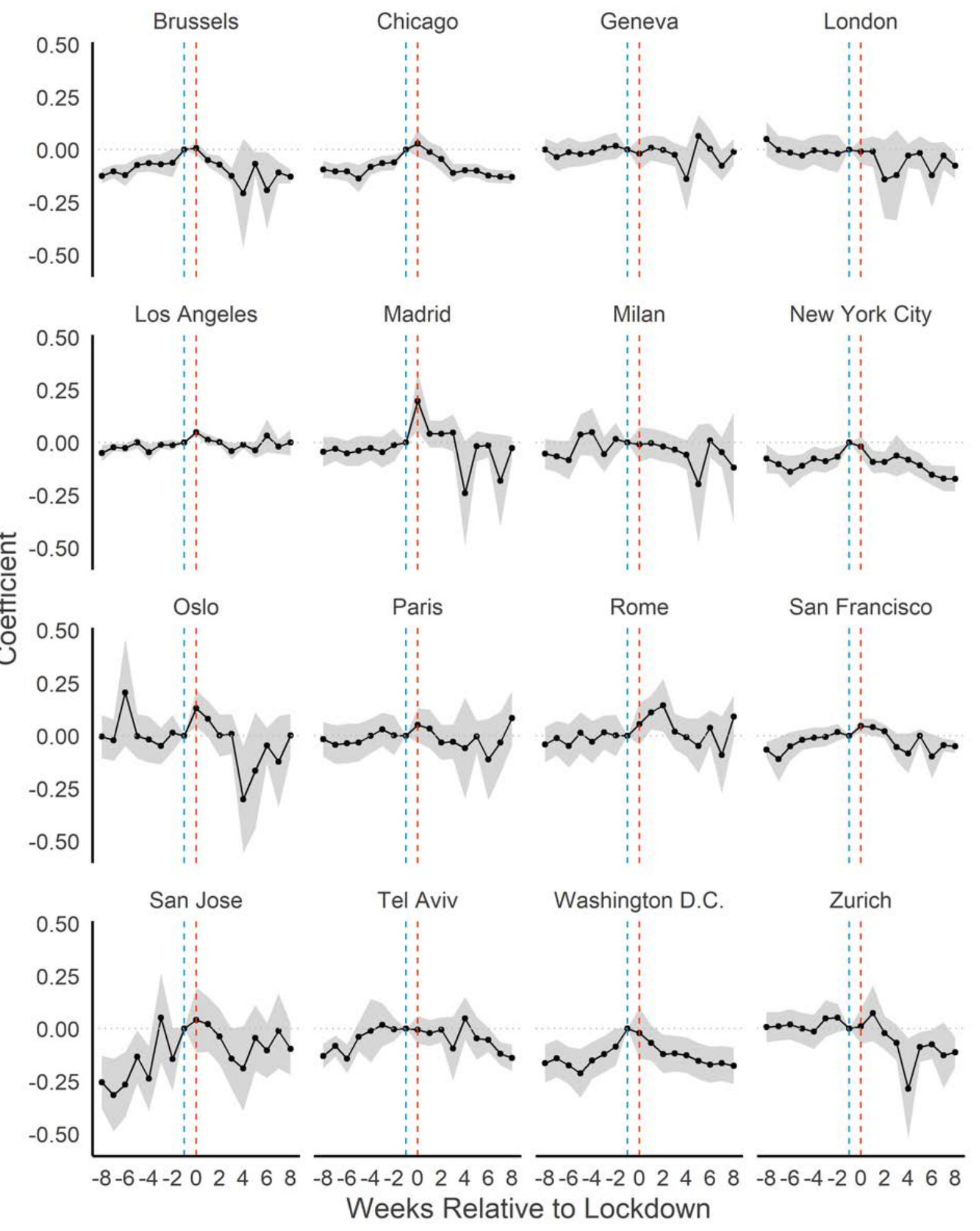

Base Week Lockdown Date 
Figure S12: Impact of COVID-19 Lockdown on Emails Sent Distinct (log) by MSA

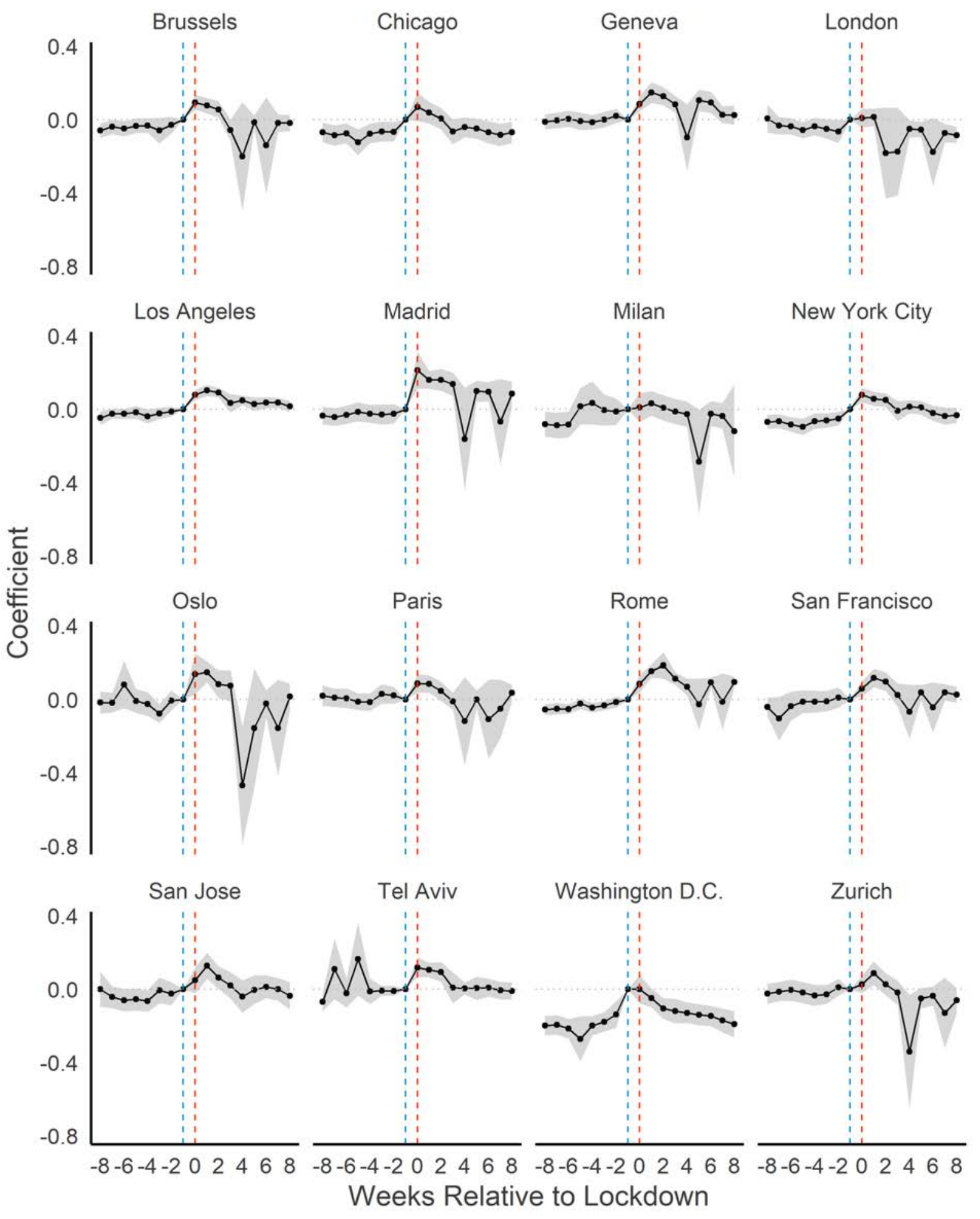

Base Week $\quad$ Lockdown Date 
Figure S13: Impact of COVID-19 Lockdown on Email Recipients (log) by MSA
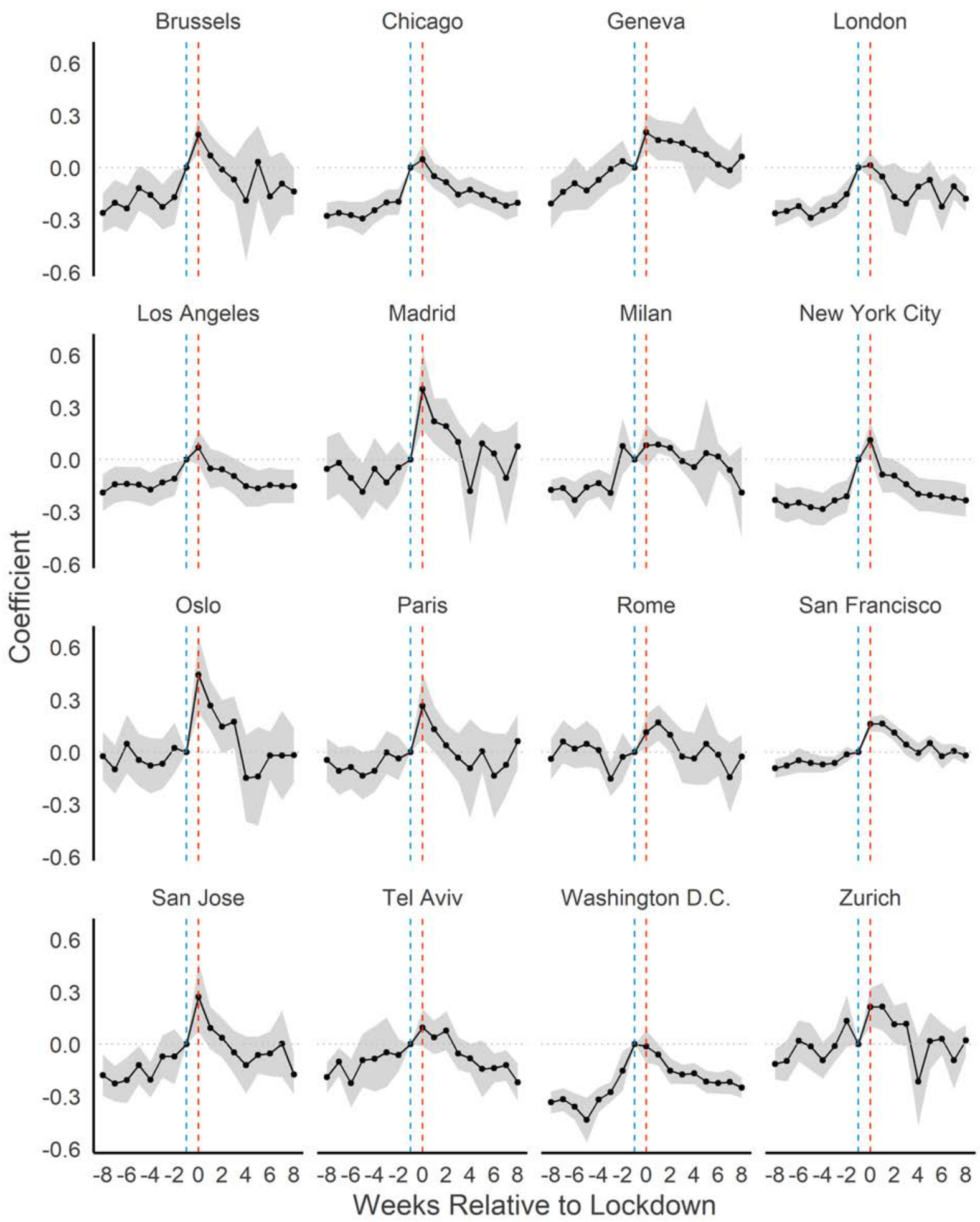

Base Week $\quad$ Lockdown Date 
Figure S14: Impact of COVID-19 Lockdown on Workday Span (log) by MSA
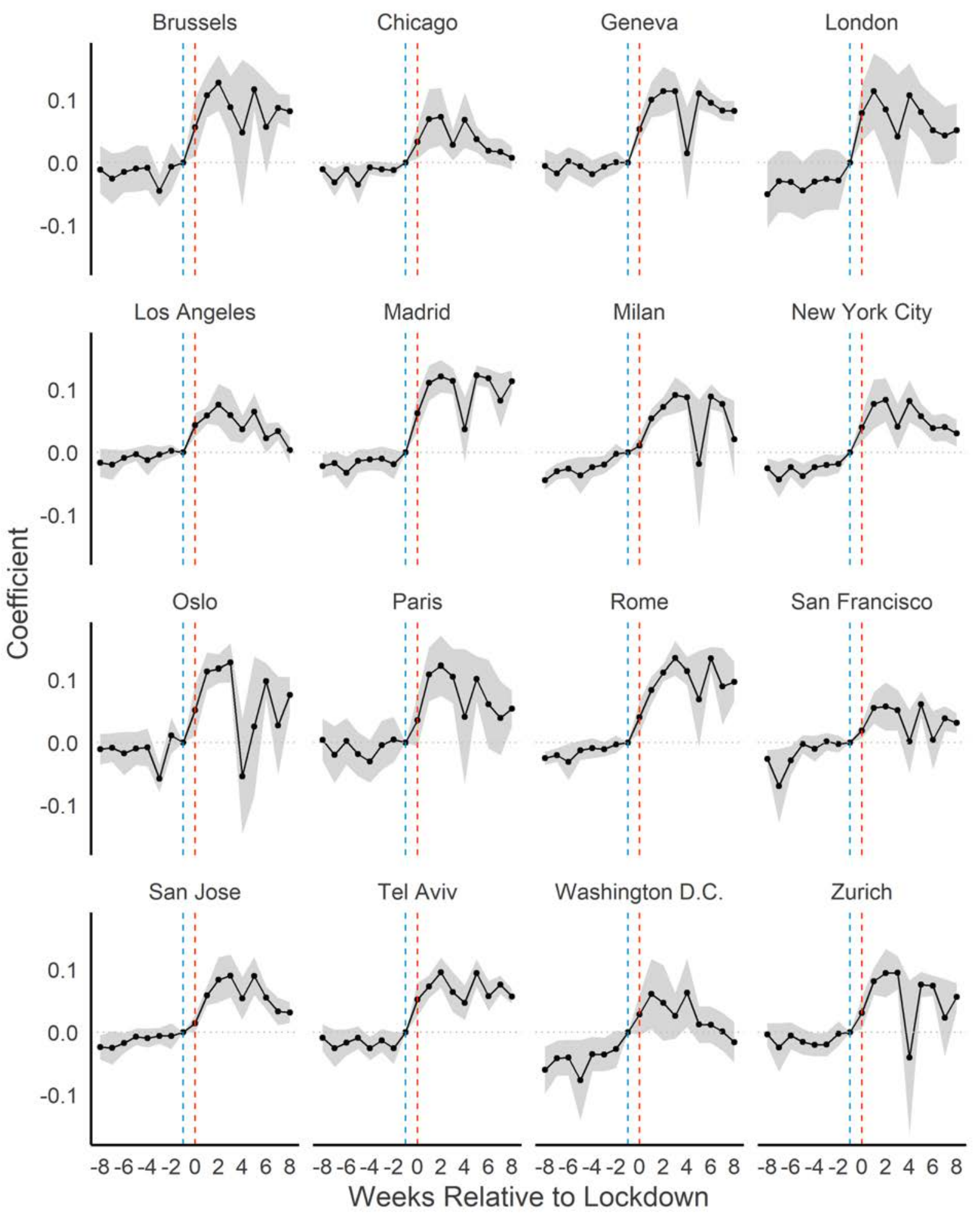

Base Week $\quad$ Lockdown Date 
Figure S15: Impact of COVID-19 Lockdown on Emails Sent After Hours (log) by MSA

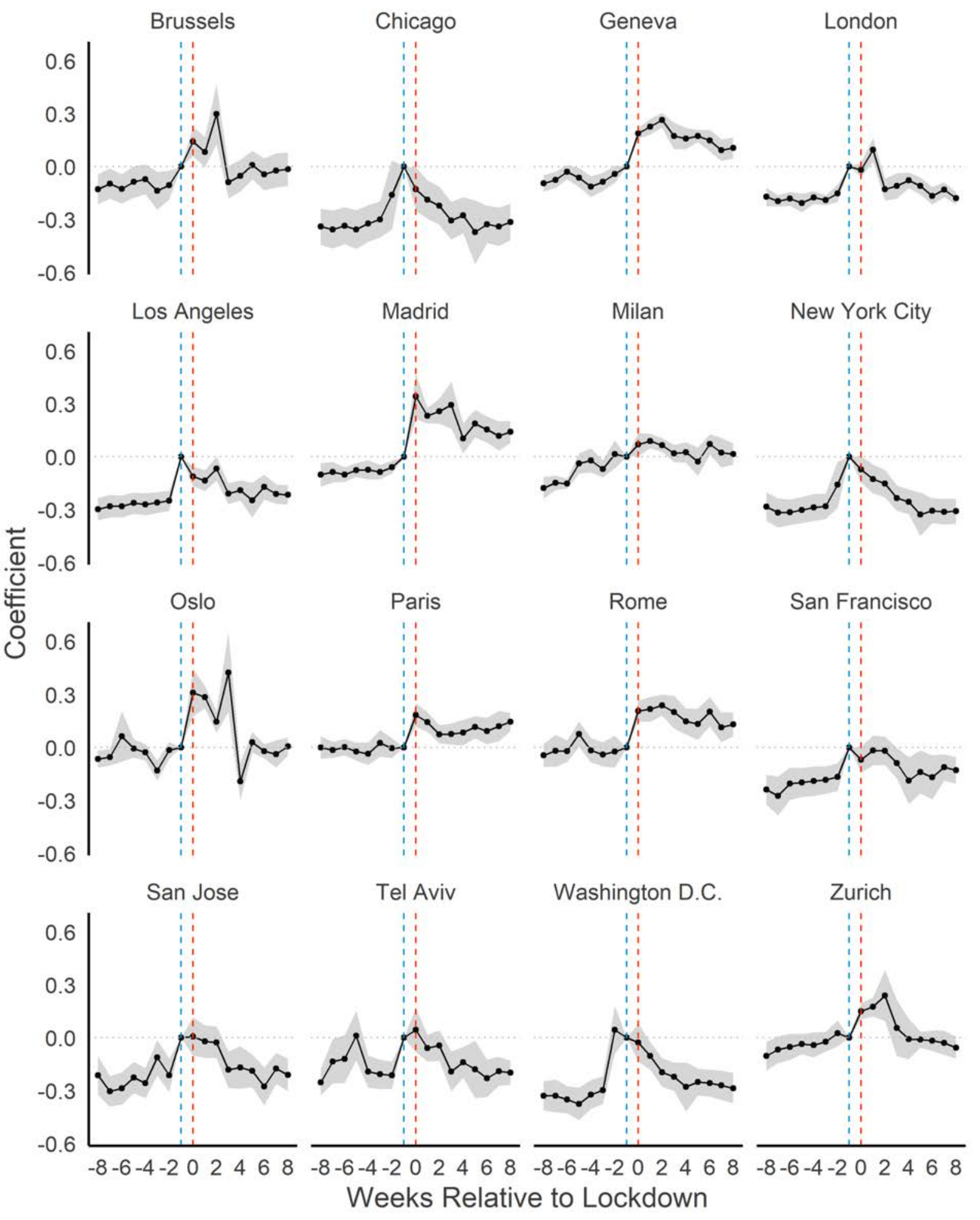

Base Week Lockdown Date 